\title{
1 Variable dynamic styles of primordial heterogeneity 2 preservation in the Earth's lower mantle
}

\author{
3 Anna J. P. Gülcher ${ }^{1, *}$, David J. Gebhardt ${ }^{1}$, Maxim D. Ballmer ${ }^{2,1,3}$, and Paul J. Tackley ${ }^{1}$ \\ $4{ }^{1}$ Institute of Geophysics, Department of Earth Sciences, ETH Zürich, Zürich, Switzerland; \\ $5 \quad{ }^{2}$ Department of Earth Sciences, University College London, London, UK \\ 6 '3Earth-Life Science Institute, Tokyo Institute of Technology, Tokyo, Japan \\ $7 \quad *$ Corresponding author: anna.guelcher@erdw.ethz.ch \\ 9 Keywords \\ 10 Earth structure, compositional heterogeneity, mantle dynamics, primordial domains, mantle \\ 11 composition, primitive material \\ Highlights \\ - Heterogeneity preservation in Earth's mantle depends on rheological contrasts \\ - High bulk moduli promote neutral buoyancy of primordial domains in the lower mantle \\ - Several styles of mantle convection and heterogeneity may occur in rocky planets \\ - Some of these styles can reconcile ancient rock preservation in a convecting mantle
}

\section{Abstract}

The evolution of the system Earth is critically influenced by the long-term dynamics, composition and structure of the mantle. While cosmochemical and geochemical constraints indicate that the lower mantle hosts an ancient primordial reservoir that may be enriched in $\mathrm{SiO}_{2}$ with respect to the upper mantle, geophysical observations and models point to efficient mass transfer and convective mixing across the entire mantle. Recent hypotheses of primordial-material preservation in a convecting mantle involve delayed mixing of intrinsically dense and/or intrinsically strong heterogeneity. Yet, the effects of composition-dependent rheology and density upon heterogeneity preservation and the dynamics of mantle mixing remain poorly understood. Here, we present twodimensional numerical models in spherical geometry, investigating the preservation styles of primordial material as a function of its physical properties (i.e., viscosity and density contrasts). We establish multiple regimes of primordial-material preservation that can occur in terrestrial planets. These include (1) efficient mixing, (2) double-layered convection with or without topography, and (3) variable styles of partial heterogeneity preservation (e.g., as diffuse domains, piles or viscous 
blobs in the lower mantle). Some of these regimes are here characterised for the first time, and all regimes are put into context with each other as a function of model parameters. The viscous-blobs and diffuse-domains regimes can reconcile the preservation of primordial domains in a convecting mantle, potentially resolving the discrepancy between geochemical and geophysical constraints for planet Earth. Several, if not all, regimes characterised here may be relevant to understand the longterm evolution of terrestrial planets in general.

\section{Introduction}

Better constraints on the composition and structure of the Earth's deep interior are essential to advance our understanding of the accretion and evolution of the Earth. While the composition of the upper(most) mantle is well constrained by the inversion of the mid-ocean ridge basalt (MORB) melting process, that of the lower mantle remains heavily debated. The composition of the upper(most) mantle that yields MORB upon partial melting is pyrolite, i.e., similar to the rock type peridotite. Estimates for lower-mantle rocks range from pyrolite to significantly silica-enriched compositions [Murakami, 2012], thus spanning Mg/Si from 1.3 (pyrolite) to 1.0 (chondritic).

Constraints from geochemistry and geophysics yield opposing interpretations concerning the dynamics and composition of the (lower) mantle. Seismic tomography studies provide evidence for the deep sinking of subducted lithosphere [e.g., van der Hilst et al., 1997], as well as the presence of deep-rooted plumes that rise through the entire mantle [French and Romanowicz, 2015]. Also, the surface expressions of plumes are spatially related to the large low shear-wave velocity provinces (LLSVP) in the lowermost mantle [Burke et al., 2008]. These observations are interpreted in terms of thermochemical convective flow that encompasses the whole mantle and efficient mantle mixing on secular timescales [van Keken and Ballentine, 1998]. On the other hand, recent seismic studies reveal sharp seismic impedance contrasts in the lower mantle that point to large-scale compositional heterogeneity, many at depths of $\sim 1000 \mathrm{~km}$ [Jenkins et al., 2017; Waszek et al., 2018]. Moreover, at least some slabs stagnate in the uppermost lower mantle (at depths between 800-1300 km) [Fukao and Obayashi, 2013, Goes et al., 2017], suggesting that modern-mantle dynamics may be in some sort of a hybrid state between whole-mantle convection with efficient mixing and layered convection with inefficient mixing.

Along with these geophysical constraints, recent studies of ${ }^{182} \mathrm{~W} /{ }^{184} \mathrm{~W}$ and ${ }^{142} \mathrm{Nd} /{ }^{143} \mathrm{Nd}$ geochemical anomalies in igneous rocks provide strong support for preservation of ancient mantle heterogeneity through Earth's history. Any anomalies in daughter nuclides ${ }^{182} \mathrm{~W}$ and ${ }^{142} \mathrm{Nd}$ of shortlived decay systems must have been formed in the first $\sim 40$ Myrs and 300 Myrs after solar-system formation, respectively. Positive and negative ${ }^{182} \mathrm{~W}$ anomalies are preserved in Archean igneous rocks 
[e.g., Touboul et al., 2012], Phanerozoic flood basalts [Rizo et al., 2016], and modern ocean island basalts [Mundl et al., 2017], pointing to the presence of "primordial" mantle heterogeneity that formed within the first $\sim 50$ million years of solar system history and has persisted up to the present day. ${ }^{142} \mathrm{Nd}$ anomalies from Archean igneous rocks [Touboul et al., 2012], and modern ocean-island basalts [Peters et al., 2018] support an early fractionation of a thereafter unmixed reservoir in the mantle. Further to this, ocean island basalts have been identified as a source of high ${ }^{3} \mathrm{He} /{ }^{4} \mathrm{He}$ signatures, which are indicative of an undegassed primordial source [Jackson et al., 2010]. The isotopic systematics of other noble gases, such as $\mathrm{Ne}$ and $\mathrm{Xe}$, support that this primordial source has been separated from the mantle within at least 500 Myrs of solar-system formation [Mukhopadhyay, 2012]. However, the volume and location of these primordial reservoir(s) in the mantle, as well as the candidate geodynamical mechanisms for long-term preservation, remain ill-constrained.

While global-scale models of mantle convection are usually characterised by efficient mixing of any initial heterogeneity, and near-homogenization of the mantle on time scales shorter than the age of the Earth [van Keken and Ballentine, 1998; Coltice and Schmalzl, 2006], variations in material properties may promote preservation of heterogeneity. For example, intrinsically-dense heterogeneity may persist in the lowermost mantle near the core-mantle boundary (CMB) in the form of piles [e.g., Li et al., 2014]. Alternatively, small, intrinsically-viscous blobs tend to resist mixing and entrainment into the MOR melting zone [Manga, 1996, Becker et al., 1999]. Recent work by Ballmer et al. [2017] has established a novel convective regime in which large, intrinsically viscous domains can persist in the mid mantle for the age of the Earth, with whole-mantle circulation being accommodated around them. The physical properties (e.g., high viscosity) required for long-term preservation of these domains are thought to be sustained by an enrichment in the strong lowermantle mineral bridgmanite (i.e., stabilised by an enrichment in silica). These suggested "bridgmaniteenriched ancient mantle structures" (BEAMS), along with piles near the CMB, are the best candidates to host primordial reservoirs in the convecting mantle.

However, the long-term preservation of BEAMS as well as of piles in the lower mantle is highly dependent on the viscosity and density contrasts between the primordial and ambient-mantle materials [e.g., Davaille, 1999; Ballmer et al., 2017]. Yet the models utilised to explore these geodynamic models of mixing in the mantle apply significant simplifications. For example, Ballmer et al. [2017] considered a Cartesian geometry and a simplified mantle rheology without plate-like behaviour. More importantly, all previous studies of thermochemical convection in the mantle have only explored a limited parameter space, and have thus been unable to map out the conditions for the various geodynamic regimes that have been proposed (e.g., piles, BEAMS, blobs, efficiently mixed mantle) to put them in context to each other. 
The goal of the present contribution is to investigate the preservation styles of primordial material in the mantle as a function of its physical properties. We systematically explore twodimensional numerical models of mantle convection and mixing over 4.5 Gyrs in a spherical annulus geometry. We establish multiple regimes of long-term convective style and mixing of primordial material with ambient-mantle pyrolite as a function of primordial physical properties (viscosity, density and bulk modulus). Finally, the applicability of these mantle convective regimes to the Earth, and other terrestrial planets is discussed.

\section{Methods}

\subsection{Numerical method and initial set-up}

In this study, we use finite-volume code StagYY [Tackley, 2008] to model mantle convection in two-dimensional spherical annulus geometry [Hernlund and Tackley, 2008]. The conservation equations for mass, momentum, energy and composition are solved on a staggered grid for a compressible fluid with an infinite Prandtl number. The modelled mantle domain is discretised by $512 \times 64$ cells. Due to vertical grid refinement near the boundary layers and near $660 \mathrm{~km}$ depth, as well as the spherical geometry, the size of grid cells varies between 15 and $50 \mathrm{~km}$ in the vertical $(\sim 25 \mathrm{~km}$ at the top and bottom boundaries and $15 \mathrm{~km}$ around the 660 phase transition) and 40 and $80 \mathrm{~km}$ in the horizontal directions, respectively. One million tracers ( $\sim 30$ tracers per cell) are used to handle non-diffusive advection of composition and temperature. We performed resolution tests with up to four times the number of grid cells and up to 45 tracers per cell. In these tests, we did not observe a significant change in the dynamics of our models. In fact, the preservation of primordial material slightly increases with increasing resolution, as expected. Thereby, our estimates of preservation remain conservative.

Boundary conditions are free-slip and isothermal at the top and bottom, achieved by imposing steadystate temperatures of 300 and $4000 \mathrm{~K}$, respectively. Thereby, our numerical experiments are purely bottom-heated (no internal heating). The initial temperature profile is an adiabat with a potential temperature of $1600 \mathrm{~K}$ plus thermal boundary layers of thickness $30 \mathrm{~km}$ at the top and bottom. On top of this distribution, random thermal perturbations of amplitude $\pm 10 \mathrm{~K}$ are applied on the cell level.

The initial condition of composition in our models is a simplified two-layered profile motivated by a fractional-crystallization sequence of the magma ocean [Elkins-Tanton, 2008; Boukaré et al., 2015]. We impose a $2230 \mathrm{~km}$-thick bridgmanitic "primordial" material layer in the lower mantle extending from $660 \mathrm{~km}$ to $2890 \mathrm{~km}$ depth, and pyrolitic material in the upper mantle. The primordial layer includes 5\% pyrolitic "noise", distributed randomly throughout the primordial layer, resulting in 
an initial primordial layer that is not a pristine fractional-crystallization end-member cumulate. Including $5 \%$ pyrolytic material in the lower mantle is consistent with the addition of $\sim 1 \%$ ferropericlase to an otherwise predominantly bridgmanitic layer, and could be related to the freezing of $\sim 5 \%$ of pyrolitic interstitial liquid.

\subsection{Treatment of mantle composition, phase changes and melting}

We consider a simplified mantle composition with three lithological components: harzburgite, basalt and primordial material. Accordingly, each tracer carries either a primordial material composition or a mechanical mixture of harzburgite and basalt. For example, the initial pyrolitic composition in the upper mantle is a mechanical mixture of $80 \%$ harzburgite and $20 \%$ basalt. To calculate the relevant density profiles of harzburgite and MORB, mantle materials are treated as a mixture of olivine and pyroxene-garnet systems that undergo different solid-solid phase transitions [as in Nakagawa et al., 2010]. Harzburgite is considered as a mixture of $75 \%$ olivine and $25 \%$ pyroxenegarnet; basalt is considered as pure pyroxene-garnet. In turn, primordial material is not defined in terms of a specific mineral composition, but solely through its material properties, which are varied as free parameters in this study. However, we have a primordial material in mind that is strongly enriched in $(\mathrm{Mg}, \mathrm{Fe}) \mathrm{SiO}_{3}$ bridgmanite. Parameters for the phase transition depths and physical properties for each mineral system, and for primordial material, are given in Table 2.

The density profiles of the relevant mantle materials that result from these parameters are plotted in Figure 1a. The density profiles of harzburgite and MORB are consistent with those from Xu et al. [2008]. The density profile of primordial material is consistent with that of a bridgmaniteenriched material with a $(\mathrm{Mg}+\mathrm{Fe}) / \mathrm{Si}$ ratio of $\sim 1.0$. For example, it resembles that of a solid solution of $50 \%$ basalt and $50 \%$ harzburgite in Xu et al. [2008]. Accordingly, our reference primordial material is enriched in $\mathrm{SiO}_{2}$ (and also slightly enriched in $\mathrm{FeO}$ ) compared to pyrolite, roughly corresponding to a material of composition $\mathrm{Mg}_{0.85} \mathrm{Fe}_{0.15} \mathrm{SiO}_{3}$ bridgmanite, or any other composition with a similar density profile. The density profile of primordial material is further altered in the lower mantle by imposing a relatively higher bulk modulus than that of the pyrolitic mantle (which is $210 \mathrm{GPa}$ ). We consider bulk moduli $K_{0, \text { prim }}$ of $225 \mathrm{GPa}$ and $230 \mathrm{GPa}$ in the lower mantle for primordial material, and explore the effects of this parameter in two model suites. An increased bulk modulus in primordial material is consistent with high-pressure experimental studies of bridgmanite [Wolf et al. 2015]. Relatively high bulk moduli result in shallower density gradients for primordial materials relative to that of pyrolite in the lower mantle, as shown in Figure $1 \mathrm{~b}$. 
Compositional anomalies carried on tracers evolve from the initial state due to melt-induced differentiation. For example, tracers in the basalt-harzburgite space undergo partial melting as a function of pressure, temperature and composition to sustain the formation of basaltic crust (for details, see Nakagawa et al., 2010). To approximate melting of primordial material, we assume that any primordial tracer is converted into a tracer with $50 \%$ basalt and $50 \%$ harzburgite once it reaches a depth of $<125 \mathrm{~km}$. While the composition of primordial material is not strictly defined, we use this ratio (50:50), as it corresponds to a (Mg+Fe)/Si ratio of $\sim 1.0$ (such as in bridgmanite). The conversion depth of $125 \mathrm{~km}$ is the relevant depth of pyroxenite melting [Pertermann and Hirschmann, 2003], and note that pyroxenes are the low-pressure polymorphs of bridgmanite. A sudden conversion is justified by the high melt productivity of pyroxenite. Such a conversion also serves to flag the material as "nonprimordial", since any melting and related degassing [Gonnermann and Mukhopadhyay, 2007] would likely destroy, or at least dilute, the ancient isotopic (e.g., noble gas or ${ }^{182} \mathrm{~W}$ ) fingerprint of the previously "primordial" material.

\subsection{Rheology}

We apply a visco-plastic rheology, assuming that the material deforms plastically after a critical depth-dependent yield stress is reached (as in Tackley, 2000; Crameri and Tackley, 2014). In this study, we use a low effective yield stress $\left(\tau_{\text {yield }}=20 \mathrm{MPa}\right.$ with a pressure-dependency of $\tau_{\text {yield }}^{\prime}=$ $0.008 \mathrm{MPa} / \mathrm{MPa}$ ), as shown in Table 1. Viscous deformation is governed by a simplified temperaturedependent Arrhenius-type viscosity law (Newtonian rheology) with parameters similar to those in Ballmer et al. [2017]:

$$
\eta(T, c)=\eta_{0} \lambda_{c} \exp \left(\frac{E_{a}}{R T}-\frac{E_{a}}{R T_{0}}\right)
$$

where $\eta_{0}$ is the reference viscosity at zero pressure and reference temperature $T_{0}(=1600 \mathrm{~K}), E_{\mathrm{a}}$ is the activation energy, $T$ the absolute temperature and $R$ is the gas constant $\left(8.314 \mathrm{~J} \mathrm{~mol}^{-1} \mathrm{~K}^{-1}\right)$. As one of the main model ingredients, we consider the compositional dependence of viscosity through prefactor $\lambda_{c}$ (see next section). For example, we impose a viscosity decrease $\left(\lambda_{P P V}=10^{-3}\right)$ at the postperovskite phase transition in the lowermost mantle, as suggested by experimental and theoretical mineral physics studies [Ammann et al. 2010]. The imposed activation energy (eq. 1) is relatively low (see Table 1), consistent with the geodetic inversions by Yang and Gurnis [2016] for the lower mantle. A low effective activation energy may represent the thermodynamic properties of lower-mantle materials, or mimic the effects of a complex rheology dependent on grain size or stress. For example, grain sizes may be relatively large in warm regions of the lower mantle, reducing the effective activation energy [e.g. Glisovic et al, 2015]. 


\subsection{Parameter study}

202

The two main model parameters explored here are the intrinsic density and viscosity contrasts of the primordial material relative to pyrolite. Varying the density contrast of primitive material relative to pyrolite, implies varying the $\mathrm{FeO}$ enrichment (or $\mathrm{Mg \# )}$ of the corresponding bridgmanitic material. The density of primordial material is shifted throughout the mantle by $\Delta \rho_{\text {prim, }}$ as shown in Figure 1 . We vary $\Delta \rho_{\text {prim }}$ in the range of $0 \%$ to $3 \%$, in increments of $0.2 \%$.

A compositionally dense primordial layer in the lower mantle is expected to delay wholemantle convection, or even promote two-layered convection [Deschamps and Tackley, 2009]. On the other hand, the dense layer traps heat coming from the core which may promote convective instability. These competing effects are integrated in the non-dimensional buoyancy ratio $B$, i.e., the ratio of the stabilizing chemical density difference over the destabilizing thermal density difference [Hansen and Yuen, 1988; Davaille, 1999]:

$$
B=\frac{\Delta \rho_{C}}{\Delta \rho_{T}}=\frac{\Delta \rho_{C}}{\rho \alpha \Delta T}
$$

where $\Delta \rho_{\mathrm{C}}$ and $\Delta \rho_{\mathrm{T}}$ are the relevant compositional and thermal density contrasts; $\rho$ is the density of the lower layer; $\alpha$ is the thermal expansivity, and $\Delta T$ the super-adiabatic temperature contrast between surface and $\mathrm{CMB}$. We calculate $B$ for relevant lower-mantle depths, thus taking depthdependent parameters $\Delta \rho_{\mathrm{c}}$ (i.e., the density difference between primordial material and pyrolite, see Fig. 1), $\rho$ (the density of primordial material) and $\alpha$ at $2000 \mathrm{~km}$ depth. Accordingly, $B$ ranges from $\sim 0.2$ to $\sim 1.7$ as $\Delta \rho_{\text {prim }}$ is explored between $0 \%$ and 3\% (see Figure 2 and extended Table 1 ). Note that $B$ is calculated from the relevant density difference between primordial material and pyrolite $\Delta \rho_{\mathrm{c}}$, whereas $\Delta \rho_{\text {prim }}$ is the density difference between primordial material and the reference primordial material (red and purple lines in Fig. $1 \mathrm{~b}$ ). An example $\Delta \rho_{\text {prim }}$ of $0.4 \%$ is visualised in Figure $1 \mathrm{~b}$ (red dashed line).

In addition, we impose a compositional viscosity contrast $\lambda_{\text {prim }}$ between primordial material and ambient mantle material (pyrolite) of a factor of 30, 50, 100, 300, 500 and 1000 in the lower mantle. The compositional viscosity contrast is switched off at depths $<660 \mathrm{~km}$. The limitation of imposing $\lambda_{\text {prim }}$ in the lower mantle is motivated by the high viscosity of bridgmanite relative to ferropericlase. Under deformation, bridgmanitic rocks are stronger than bridgmanite-ferropericlase aggregates by about 2-3 orders of magnitude in the lower mantle, as ferropericlase crystals tend to interconnect to form weak layers [Yamazaki and Karato, 2001; Girard et al., 2016]. All other physical parameters relevant to this study are listed in table 1. 


\section{Results}

We have conducted 205 numerical experiments, systematically varying the viscosity and density contrasts between primordial material and pyrolite ( $\lambda_{\text {prim }}$ and $\Delta \rho_{\text {prim, }}$, respectively), as well as the bulk modulus of primordial material, $K_{0, \text { prim }}$. The relevant model parameters and selected output variables of each case are summarised in Extended Data Table 1. Our results reveal multiple regimes of long-term convective style and mixing of primordial material through the mantle as a function of these parameters (Figure 2). Models within regime I predict little to no preservation of primordial heterogeneity after $4.5 \mathrm{Gyr}$ of model evolution. These models are characterised by low $\Delta \rho_{\text {prim }}$ and low $\lambda_{\text {prim. }}$ In this regime, whole-mantle convection induces efficient mixing and processing of mantle materials by near-surface melting, and the amount of primordial material preserved is typically $<20 \%$ (see Figure 2). In contrast, at high $\Delta \rho_{\text {prim }}$ (or at viscosity contrasts $\lambda_{\text {prim }} \geq 1000$ ), a significant amount $(>70 \%)$ of primordial material is preserved throughout model evolution. Little to no interaction between the initially imposed primordial and pyrolitic layers occurs due to double-layered convection or a delayed overturn (see below). Finally, a transient regime (III) occurs for low-to-intermediate $\Delta \rho_{\text {prim }}$ and moderate-to-high viscosity contrasts. In this regime, primordial heterogeneity is partially preserved due to several distinct styles of convective behaviour (see below). The amount of primordial material preserved in this third regime spans a rather wide range across various sub-regimes (approximately 20-70\%).

\subsection{Description of geodynamic regimes}

\subsubsection{Regime I: whole mantle convection with insignificant heterogeneity preservation}

For low $\Delta \rho_{\text {prim }}$ (thus for low buoyancy ratios $B$, i.e., stabilizing chemical buoyancy versus destabilizing thermal buoyancy) and low $\lambda_{\text {prim, }}$ all models show a similar behavior and are grouped here as regime I. Shortly after the onset of model evolution, downwellings develop from the cold thermal boundary layer at the top to drive upper-mantle circulation. These downwellings are deflected at the compositional interface near $660 \mathrm{~km}$ depth, thereby efficiently cooling the upper layer compared to the lower layer. Upper-mantle upwellings at first entrain only a very limited amount of primordial material from the lower layer. Together with the cooling of the upper mantle, the growth of a hot thermal boundary layer near the CMB sets up a density inversion across the mantle that promotes convective instability. At $0.4 \mathrm{Gyr}$, a mantle-scale overturn occurs to initiate subsequent 
efficient whole-mantle convection and mixing. At first, some intrinsically strong primordial domains remain in the centre of the convection cells. As convection patterns change through time, however, these primordial domains are subsequently entrained and soon reach the shallow upper mantle, where the primordial signature is removed due to melting (see Methods). Thinner and thinner streaks of primordial material remain for several Gyrs, but ultimately little or no compositional heterogeneity is preserved. Age-of-the-Earth mantle cross-sections in primordial composition and temperature for a representative model in regime I are shown in Figures 3a-b. All models within regime I consistently present a well-mixed mantle after 4.5 Gyr due to persistent whole-mantle convection (Fig. 3a). The radially-averaged temperature profile displays the typical signal of efficient whole-mantle convection with boundary-layer effects superimposed on a mostly adiabatic geotherm (Fig. 4a). The compositional profile confirms that primordial fraction across the mantle is (close to) zero (Fig. 4b). Finally, the radial viscosity profile chiefly reflects temperature and depth-dependency of rheology, as virtually no compositional anomalies are preserved (Fig. 4c).

\subsubsection{Regime II: Double-layered convection with significant heterogeneity preservation}

Models with high buoyancy ratios (approximately $B>0.8$ ), or with intermediate buoyancy ratios $(B>0.4)$ in combination with a very high viscosity contrast $\left(\lambda_{\text {prim }}=1000\right)$, display an opposing style of heterogeneity preservation than models in regime I. Little to no interaction between the upper and lower layers occurs. The explicit styles of preservation and mantle dynamics in this regime vary as a function of parameters and we identify three sub-regimes: II-L, II-T and II-O (as shown in Figure 2).

In regime II-L, no whole-mantle-scale overturn occurs when hot upwellings from the CMB first encounter the compositional interface. Upwellings are instead deflected at the compositional interface, giving rise to separate convective cells in the upper and lower mantle. Such a "doublelayered" convection is promoted by high buoyancy ratios (approximately B>1.2), as the positive thermal buoyancy never overcomes the negative compositional buoyancy. Nevertheless, a small amount of primordial material is entrained by upper-mantle convective currents, and some pyrolitic material is entrained by lower-mantle flow. Convection is slow, particularly in the lower layer, and the compositional interface remains mostly flat throughout model evolution (Fig. 3b). The radially averaged thermal profile highlights the related mid-mantle boundary layer (Fig 4.a). Similarly, the profiles in composition, and hence viscosity, show a distinct step at the mid-mantle interface (Figs. 4bc). These profiles are characteristic for a double-layered convective system with limited entrainment. Models in regime II-T with intermediate buoyancy ratios (approximately $0.8<B<1.2$ ) display greater deformation of the compositional interface after the onset of double-layered convection than 
models in regime II-L. Entrainment across the interface remains limited, but since $\Delta \rho_{\text {prim }}$ is relatively small compared to models in regime II-L, the dynamic pressures related to thermochemical convection (e.g., upwellings in the lower layer, and downwellings in the upper layer) are sufficient to support significant topography at the interface. As convective stresses increase with increasing $\lambda_{\text {prim, }}$ this topography becomes larger in amplitude and the regime boundary between II-L and II-T is shifted towards slightly higher $B$ (or $\Delta \rho_{\text {prim) }}$ ), as is seen in Figure 2 . Primordial material is largely confined to the lowermost mantle as a nearly uninterrupted layer with "mounds" that extend into the uppermost lower mantle (Fig. 3c). Radially averaged profiles in temperature, composition as well as viscosity show a smooth step around the undulating compositional interface (Figs. 4a-c). This regime is similar to that described by Kellogg et al. [1999].

Finally, models within sub-regime II-O are characterised by an extremely late onset of convection and slow deformation of the primordial layer. This regime occurs for very high viscosity contrasts $\lambda_{\text {prim }}$ of $\sim 1000$ in combination with high buoyancy ratios ( $B>0.8)$. Accordingly, the effective viscosity in the lower layer is very high ( 1e23 Pa.s). While pervasive convection is established in the upper layer earlyon, the onset of convection in the highly-viscous lower layer is delayed to the extent that little or no mixing occurs between the layers irrespective of the buoyancy ratio. Any hot upwellings that rise from the $\mathrm{CMB}$ only reach the compositional interface at about 4.0-4.5 Ga. Thereafter, models either display the early stages of a slow overturn, or of incipient double-layered convection, depending on $B$. We expect that these models will evolve into regimes II-L, II-T or III (see below) for model times (much) longer than the age of the Earth. Mantle cross-sections for regime II-O are shown in Figure $3 \mathrm{~d}$ and their corresponding averaged radial profiles are shown in Figures 4a-c. Due to the stabilizing behaviour of greater $B$, the boundary between regime II-O and its neighbouring regimes is inclined in $B-\lambda_{\text {prim }}$ space (i.e., shifted towards lower $\lambda_{\text {prim }}$ for greater $B$, see Fig. 2), since the II-T and III regimes appear for low $B$.

\subsubsection{Regime III: Transient mantle convection with partial heterogeneity conservation}

In regime III, moderate amounts of primordial heterogeneity are preserved over 4.5 Gyrs of model evolution time. This regime occurs for low-to-moderate density contrasts and moderate-tohigh viscosity contrasts, largely irrespective of $K_{0, p r i m}$ (Figures $2 \mathrm{a}-\mathrm{b}$ ). The regime boundary between regimes II and III occurs at a critical buoyancy number of $\sim 0.8$. For very high viscosity contrasts, however, regime II-T occurs at $B<0.8$. In this case, regime II-T is promoted by a delayed overturn (2.5 3.5 Gyr) and hence delayed entrainment of primordial heterogeneity. We expect that for model 
times larger than the age of the Earth, these cases will eventually transition to regime III. Regime III is subdivided into three sub-regimes. The age-of-the-Earth mantle cross-sections of these styles are shown in Figure 5.

In regimes III-b and III-B, primordial heterogeneity is preserved as relatively small (with a diameter of $100 \mathrm{~km}$ ) to large (several $100 \mathrm{~s}$ to $1000 \mathrm{~km}$ in diameter) blobs that reside in the mid-lower mantle, respectively. This regime occurs for $\lambda_{\text {prim }}$ of 100-1000 and relatively low buoyancy ratios, as shown in Figure 2. It expands at the expense of other sub-regimes for increasing $K_{0, \text { prim, }}$ as will be discussed in Section 3.3. Evolution starts similarly to all other models with cold downwellings in the upper layer and a delayed onset of convection in the lower layer. After ample growth of the thermal boundary layer near the $\mathrm{CMB}$, buoyant upwellings formed in the lower layer go through the compositional interface (whole-mantle overturn). As the primordial upwellings melt in the upper mantle and the pyrolitic downwellings are heated near the CMB to feed any subsequent upwellings, conveyor belts of intrinsically soft pyrolite-enhanced material are established around the mostly primordial cores of convection cells. These intrinsically strong primordial domains are disconnected from each other, and deformation (viscous dissipation) is localised within the pyrolytic conduits. Hence, primordial blobs remain mostly undeformed and poorly mixed. They slowly rotate, periodically turning over as they are heated from below. Occasionally, two blobs coagulate or are separated again, as the convection patterns re-organise through time (as is characteristic for high-Ra convection). Blobs are continuously eroded and primordial material is slowly entrained by the convecting pyrolitic mantle. Some primordial blobs are preserved through the age of the Earth and reside in the midmantle (Figs. 5a-b). The size of the surviving blobs, as well as their total volume, increases with increasing viscosity contrast $\left(\lambda_{\text {prim }}<1000\right)$, increasing $K_{0, \text { prim, }}$ and also slightly with and decreasing $B$. The parameter sub-space of the blob-regime III-b/B is significantly expanded for increasing $K_{0, p r i m}$ (as will be discussed in Section 3.3). For the small-blob " $b$ " cases, the final primordial material preservation is typically $20-30 \%$ (Figs. 2; 5a), and blobs mostly reside at a depth range of $1200-1700$ km (Fig. 4c). For the " $B$ " cases, preservation varies between $25-50 \%$, and primordial heterogeneity assumes the form of large blobs that reside at about 1000-2000 km depth (Figs. 4c, 5b). These cases are similar to the BEAMS regime described by Ballmer et al. [2017]. These regimes with blobs in the mid mantle are well distinguished in the radial viscosity and compositional profiles as distinct "hills" at the relevant depths (Figs. $4 \mathrm{~b}-\mathrm{c}$ ). In contrast, the averaged thermal profile is similar to that in regime I (Fig. 4a).

Regime III-P consists of models that display primordial heterogeneity preservation after 4.5 Gyr in the form of large primordial blobs that are largely confined to the lowermost mantle, as shown in Figure $5 c$. This regime is manifested for moderate $B$ of $0.6-0.8$ and $\lambda_{\text {prim }}$ of about $100-500$ (i.e., 
between regimes III-b/B and II-T), but is shifted to lower $B$ for $\lambda_{\text {prim }}=1000$. The initial model evolution is similar to that of regime III-b/B (see above), in which delayed hot upwellings from the CMB drive a whole-mantle overturn. Large, strong primordial domains remain within the core of convection cells at first, but subsequently settle near the $\mathrm{CMB}$ due to the relatively large negative chemical buoyancy compared to regimes III-b/B. Since their overall buoyancy remains close to neutral, however, blobs are repeatedly pushed up from the $\mathrm{CMB}$ by convective stresses, particularly as they are intermittently overheated at their base. For decreasing viscosity ratios, the "piles" tend to be less coherent, i.e., with more "diffuse" boundaries. Radial profiles of composition and viscosity in regime III-P reflect a small step in the mid-mantle with an ever-increasing primordial fraction towards the CMB (Figs. 4b-c). Similarly, the thermal profile shows a small temperature jump in the mid-mantle, since "piles" are systematically warmer than the convecting mantle (Fig 4a). Despite some morphological similarities, this regime is different from regime II-T as the volumes of preserved primordial material are systematically smaller, and covering much smaller CMB areas $(<50 \%)$. Also, the marginally stable piles originate from large blobs that are at first suspended in the mantle, instead of from a layer that is stabilised at the CMB throughout model evolution.

Finally, for a narrow parameter sub-space (i.e., relatively low viscosity contrasts and buoyancy ratios of $\sim 0.8$ ) between regimes I and II-T, primordial material is preserved as diffuse domains. Initial model behaviour is similar to cases in regime II-T, in which the first upwellings from the CMB are deflected at the compositional interface to establish a double-layered convective pattern with significant topography between the layers. However, as the density contrasts are low compared to regime II-T, the primordial material becomes entrained as thin tendrils into the upper pyrolytic layer and vice-versa. While primordial material entrained by upper-mantle upwellings is soon removed due to near-surface melting, the pyrolitic material entrained by lower-mantle downwellings accumulates in the deep mantle. Thereby, the effective density contrast between the two (upper and lower) layers progressively decreases. Accordingly, stable compositional stratification ultimately breaks down, and the system evolves from double-layered to whole-mantle convection. Hereafter, some mixed primordial-pyrolitic domains survive in the core of whole-mantle convection cells, similar to regime III-b/B (see above). Yet these mixed domains are not sufficiently strong to organise mantle flow around them, such that they are progressively entrained. Nevertheless, as the breakdown of double-layered convection occurred sufficiently late, small diffusive primordial domains remain (Fig. $5 d$ ) in the mantle after 4.5 Gyrs. This results in a radial compositional profile with a homogeneous (no "hill" or gradient) but non-zero primordial fraction throughout the mantle (Figs. 4b-c). 


\subsection{Influence of composition-dependent viscosity on heterogeneity preservation}

Each model discussed above displays a distinct effective viscosity profile through time (Figure 4c), which in turn controls convective vigour and thereby strongly affects the mixing efficiency of the mantle. Therefore, it is not obvious that these models can be directly compared to each other in terms of their predictions of material mixing in the mantle. In order to distinguish the effects of the radial viscosity profile from that of compositional viscosity dependence, we explore four additional cases with $B=0.38\left(\Delta \rho_{\text {prim }}=0.4 \%\right), K_{0, \text { prim }}=230 \mathrm{GPa}$, and various $\lambda_{\text {prim }}$ (see supplementary Figure S.1). For these cases, an additional viscosity jump at $660 \mathrm{~km}$ depth of a factor of $\lambda_{660}$ is imposed, such that the final viscosity profile is somewhat similar to that of the reference case in regime III-B ( $K_{0, \text { prim }}=230 \mathrm{GPa}$, $\lambda_{\text {prim }}=300, B=0.38$, see Fig. $5 b$ ). The corresponding cases without an additional viscosity jump at the $660\left(\lambda_{660}=1\right)$ are marked by circles Figure 2 . The additional cases with $\lambda_{660}>1$ show a similar convective vigour and surface heat flow (or top Nusselt number $\mathrm{Nu}$ ) than the reference case for regime III-B due to the similar viscosity profile. However, the preservation of primordial material is much more efficient in the reference case than in these additional cases (supplementary Table 1). Hence, we conclude that lateral viscosity contrasts between compositional domains are the critical ingredient to promote preservation, and a radial viscosity structure with strong material in the lower mantle alone is insufficient to allow for BEAMS-like formation. Imposing an additional viscosity jump in the lower mantle tends to slightly increase the amount of preserved material compared to the cases with $\lambda_{660}=$ 1 , but it does not affect the overall style of convection and heterogeneity preservation.

\subsection{Convective vigour and the effect of material bulk modulus}

As is discussed above, the intrinsic density anomaly of primordial material (i.e., $\Delta \rho_{\text {prim }}$ or $B$ ) greatly influences the style of mantle flow and the preservation of primordial heterogeneity. Greater density anomalies (and thus $B$ ) tend to promote stratification of primordial material, thereby reducing the overall convective vigour as well as heat flux through the mantle. As an indirect measure for convective vigour, Figure 6 depicts the averaged final top-boundary Nusselt number $N u_{\text {top }}$ (i.e., surface heat flux) for all numerical experiments. Note that this heat flux is sustained by convective heat transport through the mantle. Models with low $\Delta \rho_{\text {prim }}$ (regime I and III-b/B) generally display $N u_{\text {top }}$ of around 30 which is appropriate for whole-mantle convection with a Rayleigh number of about $10^{7}$, i.e., approaching an Earth-like value of $\sim 10^{8}$ [e.g., Wolstencroft et al., 2009]. On the other hand, $N u_{\text {top }}$ significantly decreases for higher $B$. Only some cases in regime III-P and III-D show $N u_{\text {top }}$ of similar values; other cases in these two regimes display significantly reduced $N u_{\text {top }}$. In double-layered regimes 
II-T and II-L, $N u_{\text {top }}$ is generally smaller than 10 , because of an additional thermal boundary layer in the mid-mantle. Regime II-O displays similarly small $N u_{\text {top }}$ due to the delayed overturn.

Finally, the primordial bulk modulus $K_{0, \text { prim }}$ also affects material mixing in the mantle (see Fig. 2). A higher bulk modulus of primordial material promotes heterogeneity preservation, particularly in the "blob" sub-regimes III-b/B, because the relevant depth-dependent density contrast $\Delta \rho_{\mathrm{c}}$ decreases towards the CMB (also seen in Figure 1b). This decrease sustains near-neutral net buoyancy of the primordial blobs in the mid-mantle, i.e., the preferred location of survival in regimes III-b/B. Thereby, primordial domains remain efficiently encapsulated within convection cells, minimizing deformation, entrainment and mixing.

\section{Discussion and conclusions}

Our results indicate that multiple regimes of primordial-material preservation can occur in terrestrial planets. Primordial material may be preserved due to (1) double-layered convection, with or without topography (regimes II-T or II-L), as (2) diffuse domains due to a delayed breakdown of double-layered convection (III-D), as (3) blobs (III-b/B), or (4) as marginally stable piles (III-P). These regimes are summarised in Figure 7 and allow for several prompting new insights into heterogeneous thermochemical convection. For example, regime III-P is very different from thermochemical-pile regimes that have been previously described in the literature [Hansen and Yuen, 1988; Davaille et al., 1999; Deschamps and Tackley, 2009; Bower et al., 2013; Li et al., 2014]: our "piles" evolve from large BEAMS-like blobs that eventually settle at the CMB. In turn, our regime II-T is more similar to previously-described thermochemical-pile regimes, being chiefly different in terms of the large initial volume of intrinsically-dense material. Along these lines, regimes III-P and III-D are described in this paper for the first time. Regimes III-b/B, while previously described by Ballmer et al. [2017], are here established for visco-plastic rheology and spherical-annulus geometry. Most importantly, all regimes described here are put in context to each other as a function of model parameters (e.g., compositional viscosity and density contrasts).

The relevance of each regime for planetary evolution depends on the real initial condition or state of the mantle before long-term convection. Our model initial condition involves a thick basal layer that is denser and stronger than the overlying mantle. The intrinsically high density and viscosity of a basal layer may be related to an enrichment in $\mathrm{FeO}$ and $\mathrm{SiO}_{2}$, respectively. For Earth-sized terrestrial planets, any enrichment in $\mathrm{SiO}_{2}$ can strongly increase the viscosity in the lower mantle, as the intrinsically-strong mineral bridgmanite is stabilised. A dominance of bridgmanite crystals (i.e., for 
$(\mathrm{Mg}+\mathrm{Fe}) / \mathrm{Si} \approx 1)$ can particularly increase viscosity by shutting off the development of interconnected weak layering of ferropericlase [Yamazaki and Karato, 2001; Girard et al., 2016], as well as by potentially allowing unrestricted grain growth.

A possible origin for the enrichment in $\mathrm{FeO}$ and/or $\mathrm{SiO}_{2}$ of the lower mantle involves incomplete core-mantle equilibration during planetary accretion. Concentrations of moderately siderophile elements in the Earth's mantle suggest that the relevant oxygen fugacities, pressures and temperatures of core formation evolved during planetary growth [Rubie, 2015]. During each stage of accretion and core formation (e.g., a giant impact), only a subset of the mantle and core equilibrate with each other [Fischer et al., 2017]. During the final stage (i.e., the Moon-forming giant impact), any remaining non-equilibrated mantle would preserve proto-Earth geochemical characteristics, potentially enhanced in $\mathrm{FeO}$ and $\mathrm{SiO}_{2}$ [Kaminski and Javoy, 2012].

Furthermore, enrichment of the basal layer may be due to fractionation during magma-ocean (MO) crystallization. A pervasive $\mathrm{MO}$ is thought to be stabilised due to the massive potential energy release during planetary accretion. As long as this MO crystallises mostly by fractional crystallization, the relevant lower-mantle cumulates are bridgmanitic [Elkins-Tanton, 2008], i.e., enhanced by $\mathrm{SiO}_{2}$ compared to pyrolite. For fractional crystallization of a (Fe-enriched) basal magma ocean [Labrosse et al., 2007; Caracas et al, 2019], cumulates may further be enhanced in FeO. In any case, the intensity of enrichment of $\mathrm{MO}$ cumulates in $\mathrm{FeO}$ and $\mathrm{SiO}_{2}$ may vary between planets as a function of accretion and differentiation scenarios (e.g., sequence of giant impacts, timescale of $\mathrm{MO}$ crystallization). Thereby, distinct regimes of material preservation as described in this paper (Figure 2) would be relevant for different terrestrial planets. Indeed, our results show that the long-term evolution of planets should be highly sensitive to their early formation history, promising that the accretion of terrestrial planets in the solar system remains on record.

For planet Earth, the viability of the various regimes described here can be tested by geophysical constraints. Seismic tomography models indicate that the Earth's mantle is compositionally homogeneous at large length scales. Any double-layering of the mantle can be ruled out as recently ( $<200$ Myrs) subducted lithosphere is seismically imaged in the deep lower mantle [e.g., van der Hilst et al., 1997]. Any large-scale heterogeneity in the Earth's lower mantle is relatively modest in terms of its seismic anomalies and/or small in volume. For example, the large low shearvelocity provinces (LLSVP) display wave-speed anomalies of just a few percent, and making up only 28 vol\% of the mantle [Burke et al., 2008; Hernlund and Houser, 2008; Cottaar and Lekic, 2016]. Lateral thermal anomalies predicted by models in regimes III-b/B and III-D are indeed modest (Figure 5), hence not contradicting tomography models. In turn, thermal anomalies predicted by models in regime III-P are probably too large to be realistic. While models in regime I (well-mixed) are consistent 
with geophysical constraints, they have difficulties to account for the preservation of primordial materials somewhere in the Earth's mantle as is evident in the geochemical record [e.g., Rizo et al., 2016; Mundl et al., 2017; Peters et al., 2018].

Along these lines, our results point towards the possible survival of sharp-to-diffuse (regimes III-b/B and III-D) primordial domains in the Earth's mid-mantle. This scenario is consistent with widespread coherent reflectors in the uppermost lower mantle (850 1100 km depth) away from major upwellings and downwellings [Waszek et al., 2018]. Receiver function studies confirm regional sharp impedance contrast in this depth range [Jenkins et al., 2017]. The stagnation of some slabs in a depth range that is similar to primordial-domain tops (while other slabs sink into the deep mantle) is consistent with our model predictions [Fukao and Obayashi, 2013] (see Figure 5b). Radial seismicanisotropy (horizontally-fast) anomalies as evident beneath stagnant slabs [Ferreira et al., 2019] may be related to focused flow around primordial blobs. In terms of seismic tomography, the lack of clear evidence for primordial domains in the mid-mantle (such as in regimes III-b/B or III-D) may be related to their small thermal anomalies (see Figure 5), as well as their anomalous composition.

None of our models, however, explicitly predict the formation of thermochemical piles in the lowermost mantle. Depending on the origin of these piles, smaller initial volumes of primordial material should yield piles with volumes similar to those of LLSVP's across the parameter range of the III-P "piles" and II-T "topography" regimes. Initial stratification of iron enrichment in the primordial layer (e.g., due to basal-magma ocean fractional crystallization [Labrosse et al., 2007]) may lead to the development of piles as well as viscous blobs in the mantle (and both with ancient origin). In turn, pile formation by segregation and accumulation of recycled oceanic crust is sensitive to the intrinsic density anomaly of basalt [Nakagawa and Tackley, 2005, Nakawaga et al., 2010] as well as the scalelength of heterogeneity [Karato, 1997]. Future work is needed to study the coexistence of primordial and recycled heterogeneity in the mantle.

Future work is also required to test the geodynamic viability of the dynamical regimes established here. For example, our viscosity law is simplified (Newtonian rheology with low activation energy) and our effective yield stress at the surface is relatively low. Furthermore, we investigated present-day Earth thermal conditions. Early-Earth mantle and core temperatures are thought to be higher than today [Andrault et al., 2016], enhancing convective vigour and thereby mantle mixing in numerical models, and future work should include this in the initial set-up of the models. Moreover, internal heating is switched off in the current models. While significant heat production within primordial domains is likely to impede preservation, we note that bridgmanitic magma-ocean cumulates are unlikely to incorporate any significant levels of highly-incompatible elements, including radioactive nuclides. Finally, geometrical limitations of our model setup (2D spherical annulus) do not 
allow for efficient mixing by the interaction of toroidal and poloidal flow components [Ferrachat and Ricard, 1998; Coltice and Schmalzl, 2006]. Additional efforts are needed to quantify the impact of compositional rheology on mantle convection and mixing in terms of focusing deformation around viscous blobs in 3D geometry [Merveilleux du Vignaux and Fleitout, 2001].

Regardless of these current limitations, our results provide a quantitative and testable framework for the preservation of primordial materials in a convecting mantle. Some of the regimes established here are very promising in terms of their potential to resolve the discrepancy between geochemical and geophysical constraints for planet Earth: while geochemical data provides clear evidence for long-term primordial material preservation, geophysical constraints strongly suggest convection (and mixing) across the whole mantle. Our work is a first step towards mapping out potential geodynamical regimes that can resolve this discrepancy, as well as guide our understanding of the evolution of terrestrial planets in general.

\section{Acknowledgements}

We thank prof. Bernhard Steinberger and one anonymous reviewer, whose thoughtful and thorough reviews improved the quality of this manuscript significantly. This study was funded by the ETH Zürich grant ETH-33 16-1. All numerical simulations were performed on ETH Zürich's Euler cluster. The opensource software ParaView (http://paraview.org) was used for 2D visualisation.

\section{Additional information}

Supplementary Data items are available in the online version of the paper. 


\section{References}

1. Ammann, M.W., Brodholt, J.P., Wookey, J., and Dobson, D.P. (2010). First-principles constraints on diffusion in lower-mantle minerals and a weak $D^{\prime \prime}$ layer. Nature, 465(7297), 462-465, doi:10.1038/nature09052.

2. Andrault, D., Monteux, J., Le Bars, M. and Samuel, H. (2016). The deep Earth may not be cooling down. Earth and Planetary Science Letters, 443, 195-203

3. Ballmer, M.D., Houser, C., Hernlund, J.W., Wentzcovitch, R.M., and Hirose, K. (2017). Persistence of strong silica-enriched domains in the Earth's lower mantle. Nature Geoscience, 10(3), 236-240, doi:10.1038/ngeo2898.

4. Becker, T.W., Kellogg, J.B., and O'Connell, R.J. (1999). Thermal constraints on the survival of primitive blobs in the lower mantle. Earth and Planetary Science Letters, 171(3), 351-365, doi:10.1016/s0012$821 \times(99) 00160-0$.

5. Boukaré, C.E., Ricard, Y., and Fiquet, G. (2015). Thermodynamics of the MgO-FeO-SiO2 system up to $140 \mathrm{GPa}$ : Application to the crystallization of Earth's magma ocean. Journal of Geophysical Research: Solid Earth, 120(9), 6085-6101, doi:10.1002/2015jb011929.

6. Bower, D.J., Gurnis, M., and Seton, M., (2013). Lower mantle structure from paleogeographically constrained dynamic Earth models. Geochemistry, Geophysics, Geosystems, 14(1), 44-63, doi:10.1029/2012gc004267.

7. Burke, K., Steinberger, B., Torsvik, T. H., and Smethurst, M. A. (2008). Plume Generation Zones at the margins of Large Low Shear Velocity Provinces on the core-mantle boundary. Earth and Planetary Science Letters, 265(1-2), 49-60. https://doi.org/10.1016/j.epsl.2007.09.042

8. Caracas, R., Hirose, K., Nomura, R., and Ballmer, M.D. (2019). Melt-crystal density crossover in a deep magma ocean. Earth and Planetary Science Letters, 516, 202-211.

9. Coltice, N., and Schmalzl, J. (2006). Mixing times in the mantle of the early Earth derived from 2-D and 3-D numerical simulations of convection. Geophysical Research Letters, 33(23), doi:10.1029/2006gl027707.

10. Cottaar, S., and Lekic, V. (2016). Morphology of seismically slow lower-mantle structures. Geophysical Journal International, 207(2), 1122-1136. https://doi.org/10.1093/gii/ggw324

11. Crameri, F., and Tackley, P.J. (2014). Spontaneous development of arcuate single-sided subduction in global 3-D mantle convection models with a free surface. Journal of Geophysical Research: Solid Earth, 119(7), 5921-5942, doi:10.1002/2014jb010939.

12. Davaille, A. (1999). Two-layer thermal convection in miscible viscous fluids. Journal of Fluid Mechanics (Vol. 379). https://doi.org/10.1017/S0022112098003322

13. Deschamps, F., and Tackley, P.J. (2009). Searching for models of thermo-chemical convection that explain probabilistic tomography. II-Influence of physical and compositional parameters. Physics of the Earth and Planetary Interiors, 176(1-2), 1-18, doi:10.1016/j.pepi.2009.03.012.

14. Elkins-Tanton, L. (2008). Linked magma ocean solidification and atmospheric growth for Earth and Mars, Earth and Planetary Science Letters. 271(1-4), 181-191, doi:10.1016/j.epsl.2008.03.062.

15. Ferrachat, S., and Ricard, Y. (1998). Regular vs. chaotic mantle mixing. Earth and Planetary Science Letters, $155,75-86$ 
16. French, S.W., and Romanowicz, B. (2015). Broad plumes rooted the base of the Earth's mantle beneath major hotspots. Nature, 525(7567), 95-99, doi:10.1038/nature14876.

17. Fukao, Y., and Obayashi, M. (2013). Subducted slabs stagnant above, penetrating through, and trapped below the 660 km discontinuity. Journal of Geophysical Research: Solid Earth, 118(11), 5920-5938. https://doi.org/10.1002/2013JB010466

18. Girard, J., Amulele, G., Farla, R., Mohiuddin, A., and Karato, S.I. (2016). Shear deformation of bridgmanite and magnesiowüstite aggregates at lower mantle conditions. Science, 351(6269), 144-147. https://doi.org/10.1126/science.aad3113

19. Glišovic, P., Forte, A.M., and Ammann, M.W. (2015). Variations in grain size and viscosity based on vacancy diffusion in minerals, seismic tomography, and geodynamically inferred mantle rheology. Geophysical Research Letters, 42(15), 6278-6286. https://doi.org/10.1002/2015GL065142

20. Goes, S., Agrusta, R., van Hunen, J. and Garel, F. (2017). Subduction-transition zone interaction: a review. Geosphere, 13 (3): 644-664.

21. Gonnermann, H.M., and Mukhopadhyay, S. (2007). Non-equilibrium degassing and a primordial source for helium in ocean-island volcanism. Nature, 449(7165), 1037-1040. https://doi.org/10.1038/nature06240

22. Hansen, U., and Yuen, D.A. (1988). Numerical simulations of thermal-chemical instabilities at the core mantle boundary. Nature, 334(6179), 237-240

23. Hernlund, J.W., and Houser, C. (2008). The statistical distribution of seismic velocities in Earth's deep mantle. Earth and Planetary Science Letters, 265(3): 423-437. Doi:10.1016/j.epsl.2007.10.042

24. Hernlund, J.W., and Tackley, P.J. (2008). Modeling mantle convection in the spherical annulus. Physics of the Earth and Planetary Interiors, 171(1-4), 48-54, doi:10.1016/j.pepi.2008.07.037.

25. Jackson, M.G., Carlson, R.W., Kurz, M.D., Kempton, P.D., Francis, D., and Blusztajn, J. (2010). Evidence for the survival of the oldest terrestrial mantle reservoir. Nature, 466(7308), 853-856, doi:10.1038/nature09287.

26. Jenkins, J., Deuss, A., and Cottaar, S. (2017). Converted phases from sharp $1000 \mathrm{~km}$ depth mid-mantle heterogeneity beneath Western Europe. Earth and Planetary Science Letters, 459, 196-207, doi:10.1016/j.epsl.2016.11.031.

27. Kaminski, E., and Javoy, M. (2013). A two-stage scenario for the formation of the Earth's mantle and core. Earth and Planetary Science Letters, 365, 97-107

28. Karato, S. (1997). On the separation of crustal component from subducted oceanic lithosphere near the $660 \mathrm{~km}$ discontinuity. Earth and Planetary Science Letters, 99(1-2), 103-111

29. Kellogg, L.H., Hager, B.H., and van der Hilst, R.D. (1999). Compositional stratification in the deep mantle. Science, 283(5409), 1881-1884. DOI: 10.1126/science.283.5409.1881

30. Labrosse, S., Hernlund, J.W., and Coltice, N. (2007). A crystallizing dense magma ocean at the base of the Earth's mantle. Nature, 450(7171), 866-869. https://doi.org/10.1038/nature06355

31. Li, M., McNamara, A. K., and Garnero, E.J. (2014). Chemical complexity of hotspots caused by cycling oceanid crust through mantle reservoirs. Nature Geoscience, 7, 366-370. https://doi.org/10.1038/ngeo2120

32. Manga, M. (1996). Mixing of heterogeneities in the mantle: Effect of viscosity differences. Geophysical Research Letters, 23(4), 403-406, doi:10.1029/96gl00242. 
33. Merveilleux du Vignaux, N., and Fleitout, L. (2001). stretching and mixing of viscous blobs in Earth's mantle. Journal of Geophysical Research, 106(B12), 30.893-30.908

34. Mukhopadhyay, S. (2012). Early differentiation and volatile accretion recorded in deep-mantle neon and xenon. Nature, 486(7401), 101-104, doi:10.1038/nature11141.

35. Mundl, A., Touboul, M., Jackson, M.G., Day, J.M.D., Kurz, M.D., Lekic, V., Helz, R.T., and Walker, R.J. (2017). Tungsten-182 heterogeneity in modern ocean island basalts, Science, 356(6333), 66-69, doi:10.1126/science.aal4179.

36. Murakami, M., Ohishi, Y., Hirao, N., and Hirose, K. (2012). A perovskitic lower mantle inferred from highpressure, high-temperature sound velocity data. Nature, 485(7396), 90-94. https://doi.org/10.1038/nature11004

37. Nakagawa, T., Tackley, P.J., Deschamps, F., Connolly, J.A.D. (2010). The influence of MORB and harzburgite composition on thermo-chemical mantle convection in a 3-D spherical shell with self-consistently calculated mineral physics. Earth and Planetary Science Letters, 296 (3-4), 403-412.

38. Nakawaga, T. and Tackley, P.J. (2005). Deep mantle flow and thermal evolution of the Earth's core in thermochemical multiphase models of mantle convection. Geochemistry, Geophysics, Geosystems, 6(8), Q08003, doi:10.1029/2005GC000967.

39. Pertermann, M., and Hirschmann, M.M. (2003). Partial melting experiments on a MORB-like pyroxenite between 2 and $3 \mathrm{GPa}$ : Constraints on the presence of pyroxenite in basalt source regions from solidus location and melting rate. Journal of Geophysical Research: Solid Earth, 108(B2), 1-17. https://doi.org/10.1029/2000JB000118

40. Peters, B.J., Carlson, R.W., Day, J.M.D., and Horan, M.F. (2018). Hadean silicate differentiation preserved by anomalous ${ }^{142} \mathrm{Nd} /{ }^{144} \mathrm{Nd}$ ratios in the Réunion hotspot source. Nature, 555(7694), 89-93, doi:10.1038/nature25754.

41. Rizo, H., Walker, R.J., Carlson, R.W., Horan, M.F., Mukhopadhyay, S., Manthos, V., Francis, D., and Jackson, M.G. (2016). Preservation of Earth-forming events in the tungsten isotopic composition of modern flood basalts. Science, 352(6287), 809-812, doi:10.1126/science.aad8563.

42. Rubie, D.C., Jacobson, S.A., Orbidelli, A., O’Brien, D.P., Young, E.D., de Vries, J., Nimmo, F., Palme, H., and Frost, D.J. (2015). Accretion and differentiation of the terrestrial planets with implications for the compositions of early-formed Solar System bodies and accretion of water. Icarus, 248, 89-108.

43. Tackley, P.J. (2000). Self-consistent generation of tectonic plates in time- dependent, three-dimensional mantle convection simulations. Geochemistry, Geophysics, Geosystems, 1, paper number $2000 \mathrm{GC} 000043$

44. Tackley, P.J. (2008). Modelling compressible mantle convection with large viscosity contrasts in a threedimensional spherical shell using the yin-yang grid. Physics of the Earth and Planetary Interiors, 171(1-4), 7-18, doi:10.1016/j.pepi.2008.08.005.

45. Tackley, P.J., Ammann, M., Brodholt, J.P., Dobson, D.P. and Valencia, D. (2013). Mantle dynamics in SuperEarths: post-perovskite rheology and self-regulation of viscosity. Icarus, 225(1), 50-61.

46. Touboul, M., Puchtel, I.S., and Walker, R.J. (2012). ${ }^{182}$ W Evidence for Long-Term Preservation of Early Mantle Differentiation Products. Science, 335(6072), 1065-1069, doi:10.1126/science.1216351.

47. van der Hilst, R.D., Widiyantoro, S., and Engdahl, E.R. (1997). Evidence for deep mantle circulation from global tomography. Nature, 386(6625), 578-584, doi:10.1038/386578a0. 
48. van Keken, P., and Ballentine, C. (1998). Whole-mantle versus layered mantle convection and the role of a high-viscosity lower mantle in terrestrial volatile evolution. Earth and Planetary Science Letters, 156(1-2), 19-32, doi:10.1016/s0012-821x(98)00023-5.

49. Waszek, L., Schmerr, N.C., and Ballmer, M.D. (2018). Global observations of reflectors in the mid-mantle with implications for mantle structure and dynamics. Nature Communications, 9(1), doi:10.1038/s41467017-02709-4.

50. Wolf, A.S., Jackson, J.M., Dera, P., and Prakapenka, V.B. (2015). The thermal equation of state of (Mg, $\mathrm{Fe}) \mathrm{SiO} 3$ bridgmanite (perovskite) and implications for lower mantle structures. Journal of Geophysical Research: Solid Earth, 120(11), 7460-7489, doi:10.1002/2015jb012108.

51. Wolstencroft, M., Davies, J.H. and Davies, D.R. (2009), Nusselt-Rayleigh number scaling for spherical shell Earth mantle simulation up to a Rayleigh number of $10^{9}$. Physics of the Earth and Planetary Interiors, doi:10.1016/l.pepi20009.05.002

52. Xu, W., Lithgow-Bertelloni, C., Stixrude, L., and Ritsema, J. (2008). The effect of bulk composition and temperature on mantle seismic structure, Earth and Planetary Science Letters, 275(1-2), 70-79, doi:10.1016/j.epsl.2008.08.012.

53. Yamazaki, D., and Karato, S. (2001). Some mineral physics constraints on the rheology and geothermal structure of Earth's lower mantle. American Mineralogist, 86(4), 385-391, doi:10.2138/am-2001-0401.

54. Yang, T., and Gurnis, M. (2016). Dynamic topography, gravity and the role of lateral viscosity variations from inversion of global mantle flow. Geophysical Journal International, 207(2), 1186-1202, doi:10.1093/gji/ggw335.

55. Zhao, D. (2001). Seismic structure and origin of hotspots and mantle plumes. Earth and Planetary Science Letters, 192(3), 251-265, doi:10.1016/s0012-821x(01)00465-4. 


\section{FIGURES}
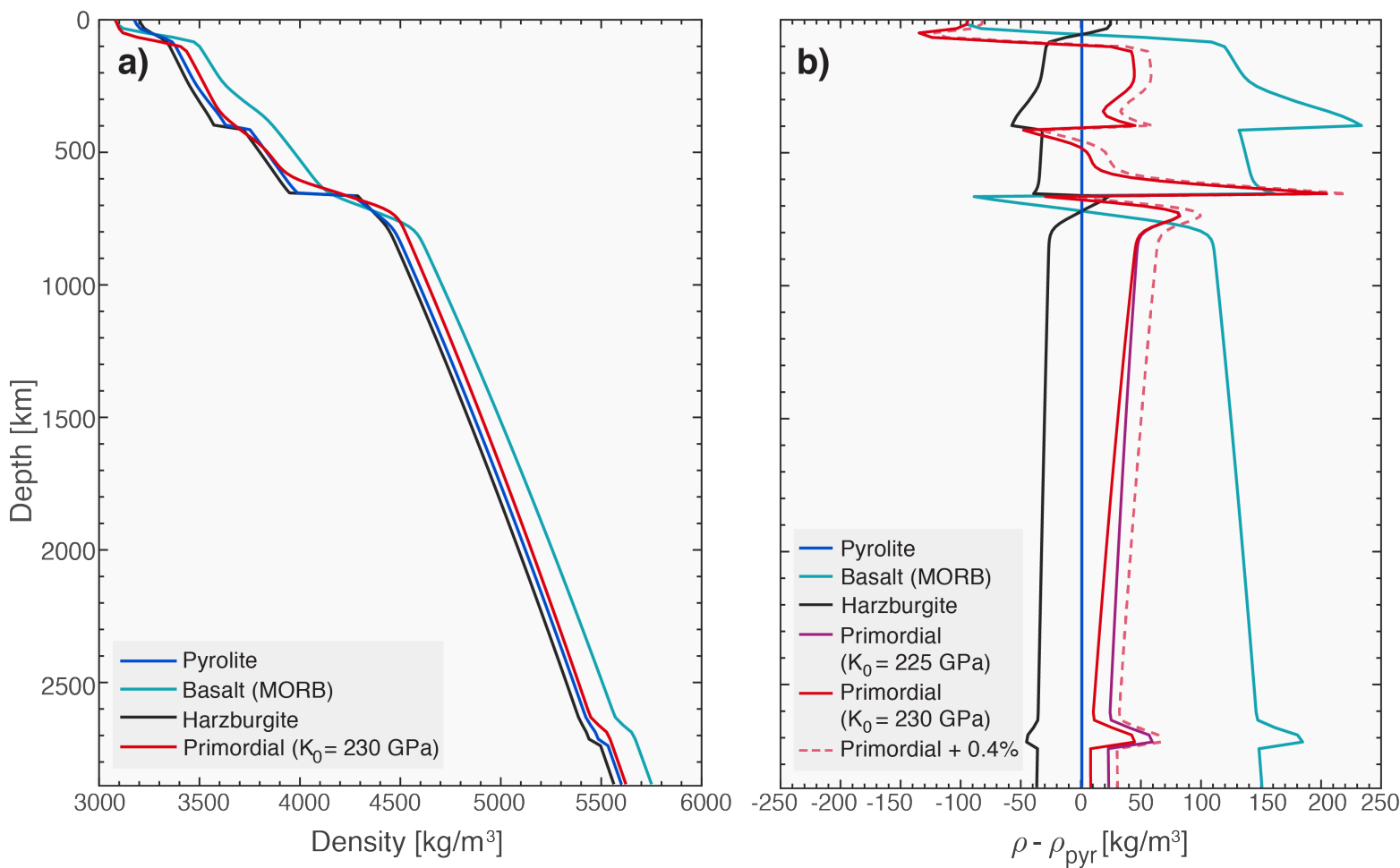

Figure 1 - Density profiles for mantle materials used in our simulations. a) Density profiles for basalt (light blue), harzburgite (black), pyrolite (dark blue), and primordial material (red). b) Relative density contrasts with depth for mantle materials relative to that of pyrolytic material. The primordial material shown as red solid and dashed lines has a bulk modulus of $K_{0, p r i m}$ $=230 \mathrm{GPa}$ in the lower mantle. The primordial material shown as purple solid line has a bulk modulus of $K_{0, p r i m}=225 \mathrm{GPa}$ in the lower mantle. 
a) $\mathrm{K}_{0, \text { prim }}=225 \mathrm{GPa}$

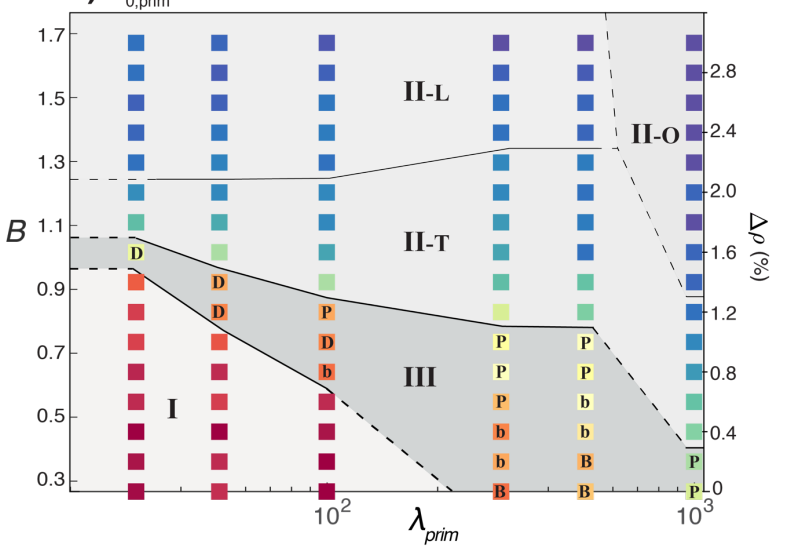

b) $\mathrm{K}_{0, \text { prim }}=230 \mathrm{GPa}$

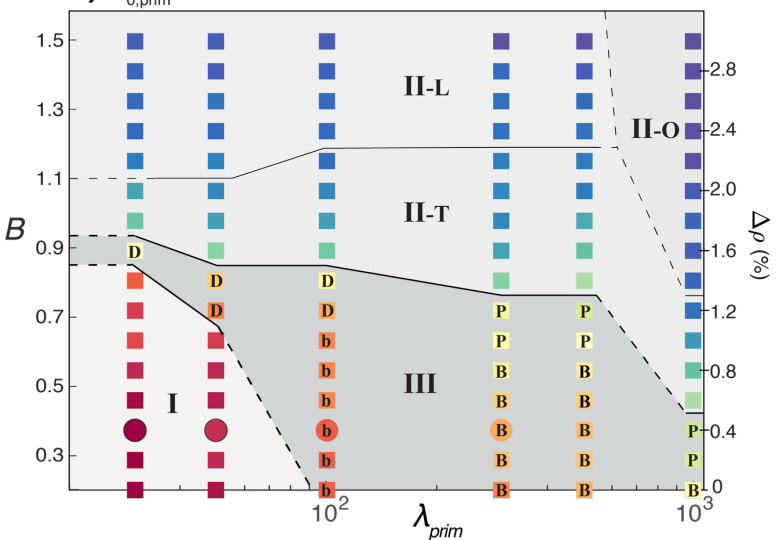

Preserved primordial material $(\%$

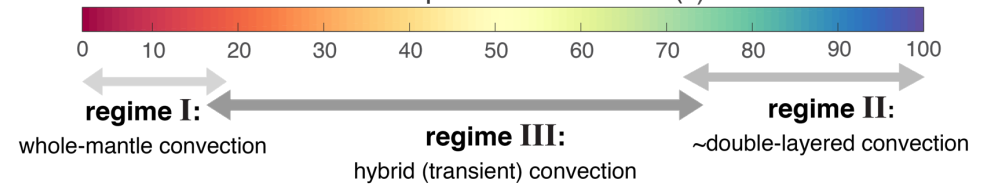

Figure 2 - Summary of model results as a function of compositional density and viscosity contrasts, and for (a) $K_{0, p r i m}=225$ GPa and (b) $K_{0, p r i m}=230 \mathrm{GPa}$. The vertical axis gives the initial Buoyancy number B, taken at $2000 \mathrm{~km}$ depth (see Methods), or its equivalent shift in density of primordial material $\Delta \rho_{\text {prim. }}$. The horizontal axis gives the viscosity contrast $\lambda_{\text {prim }}$ between primordial and pyrolytic material in the lower mantle. The color scale depicts the fraction of primordial material remaining in the mantle at 4.5 Gyr. Regime boundaries are established based on the amount of primordial preservation, and mantle evolution (see text): (I) insignificant heterogeneity preservation; (II) significant heterogeneity preservation due to doublelayered convection without ("L") or with ("T") topography, and due to a very late overturn ("O"); (III) moderate heterogeneity preservation as diffuse domains (" $D$ "), marginally stable piles (" $P$ ") or small-to-large blobs (" $b$ " to " $B$ "). 


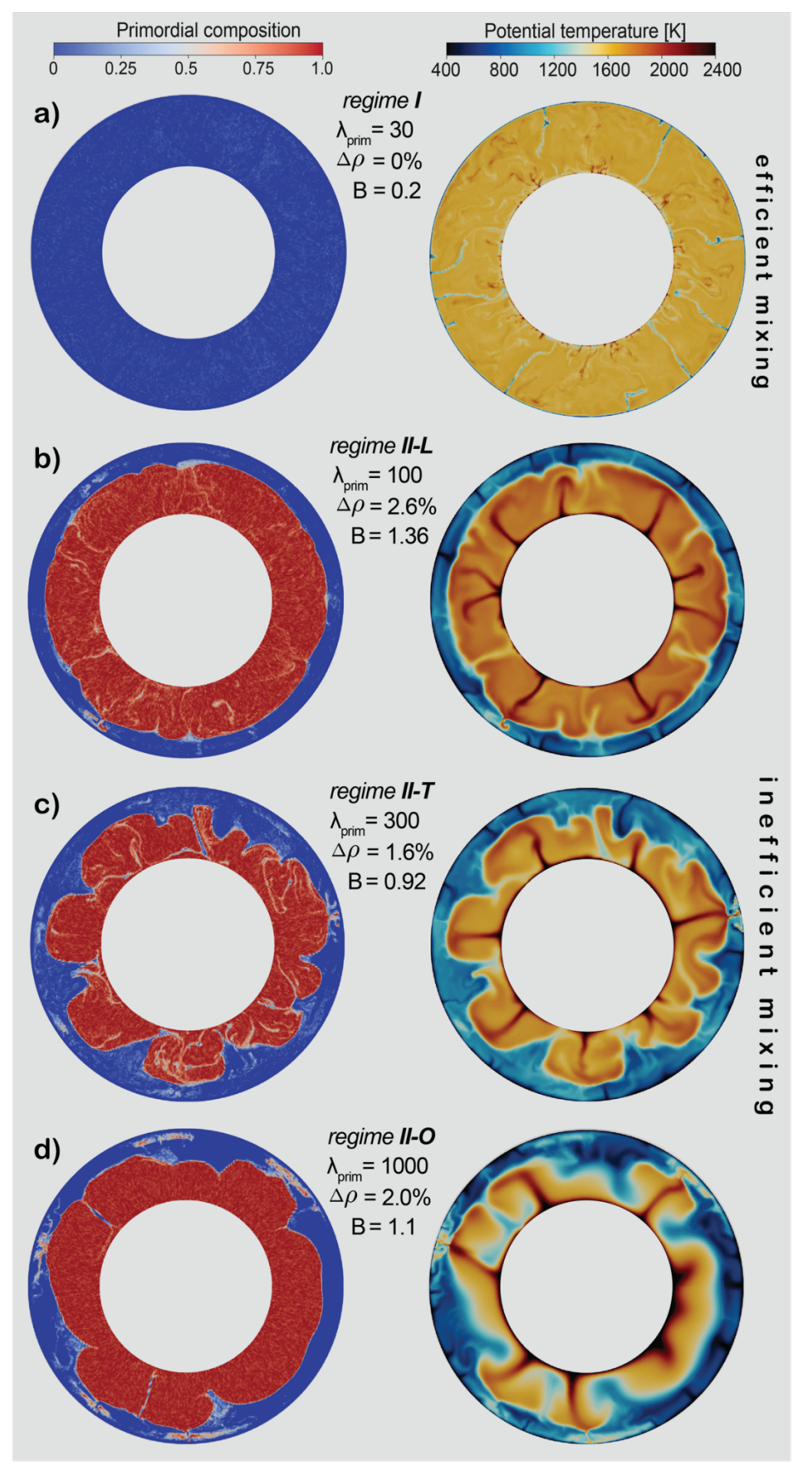

Figure 3 - Mantle sections for regimes I (a) and regime II (b-d) at 4.5 Gyr model time. The left and right columns show composition (red: primordial material; blue: harzburgite-basalt mechanical mixture) and potential temperature, respectively. For all cases shown, $K_{0, p r i m}=230 \mathrm{GPa} ; \lambda_{\text {prim, }} \Delta \rho$ and $B$ as labelled. 
a) Temperature

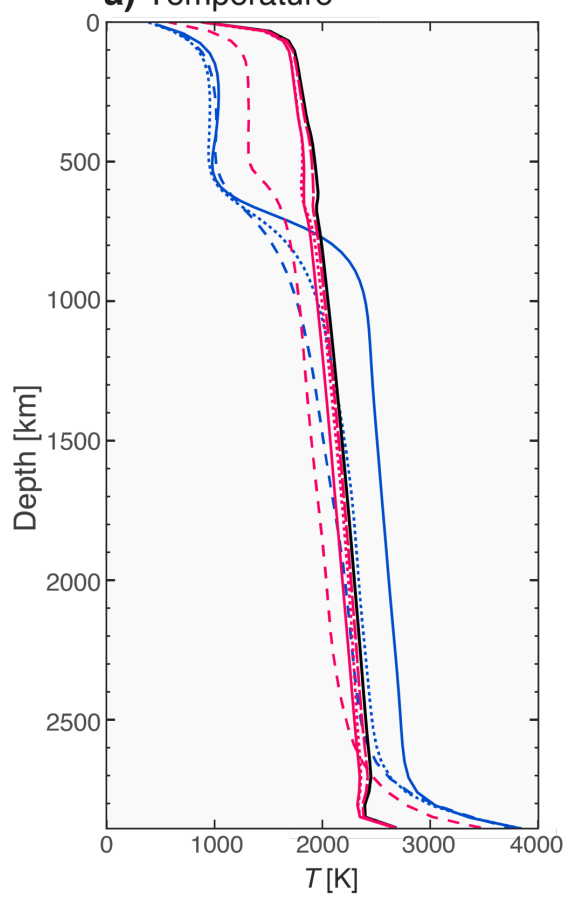

b) Primordial fraction

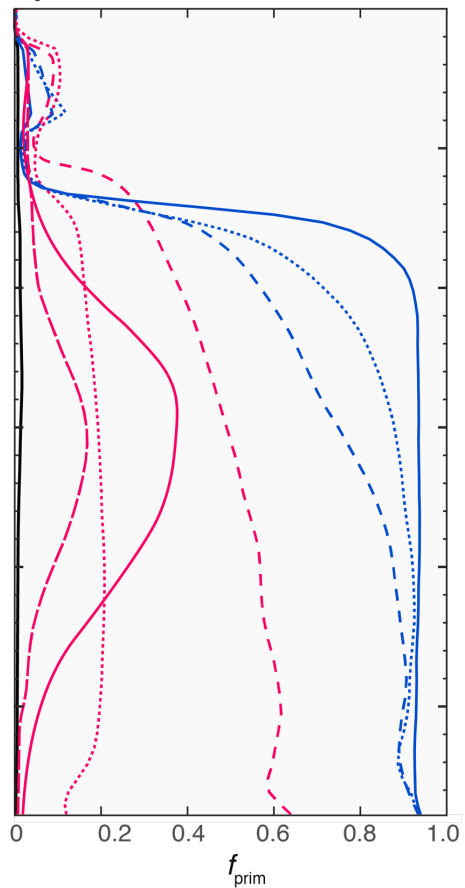

c) Viscosity

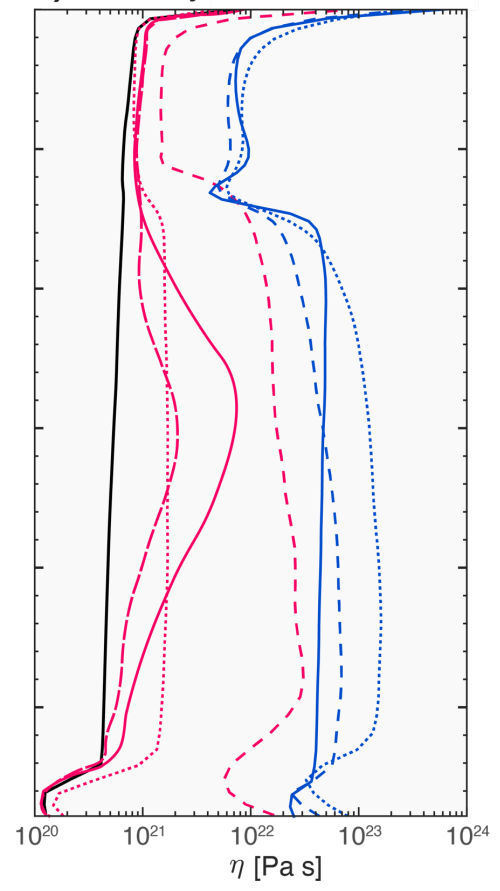

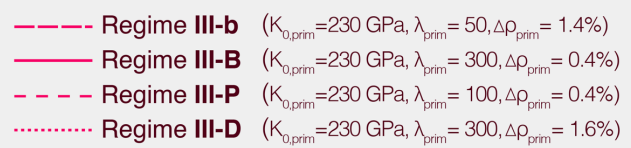

Figure 4-Averaged radial profiles of a) temperature, b) primordial fraction and c) viscosity for the various regimes and subregimes of heterogeneity preservation described here (see Figure 2). The models correspond to the example cases shown in Figures 3 and 5 and are representative for a given (sub-)regime. The radial profiles are spatially linearly averaged (temperature and primordial fraction) or a geometrical mean (viscosity), as well as linearly averaged over time (between model times 4.0 and $4.5 \mathrm{Ga}$ ). At depths $<125 \mathrm{~km}$, the primordial fraction is zero because of the tracer conversion from primordial material into $\mathrm{Bs}-\mathrm{Hz}$ at this depth (see Methods). That the viscosity decrease in the lowermost mantle is only moderate is explained by the regional stability of post-perovskite in the lower mantle. For the double-layered convection regimes (II), no to little viscosity decrease is observed in the lowermost mantle due to the high temperatures at great pressures, which preclude any stabilization of post-perovskite. 


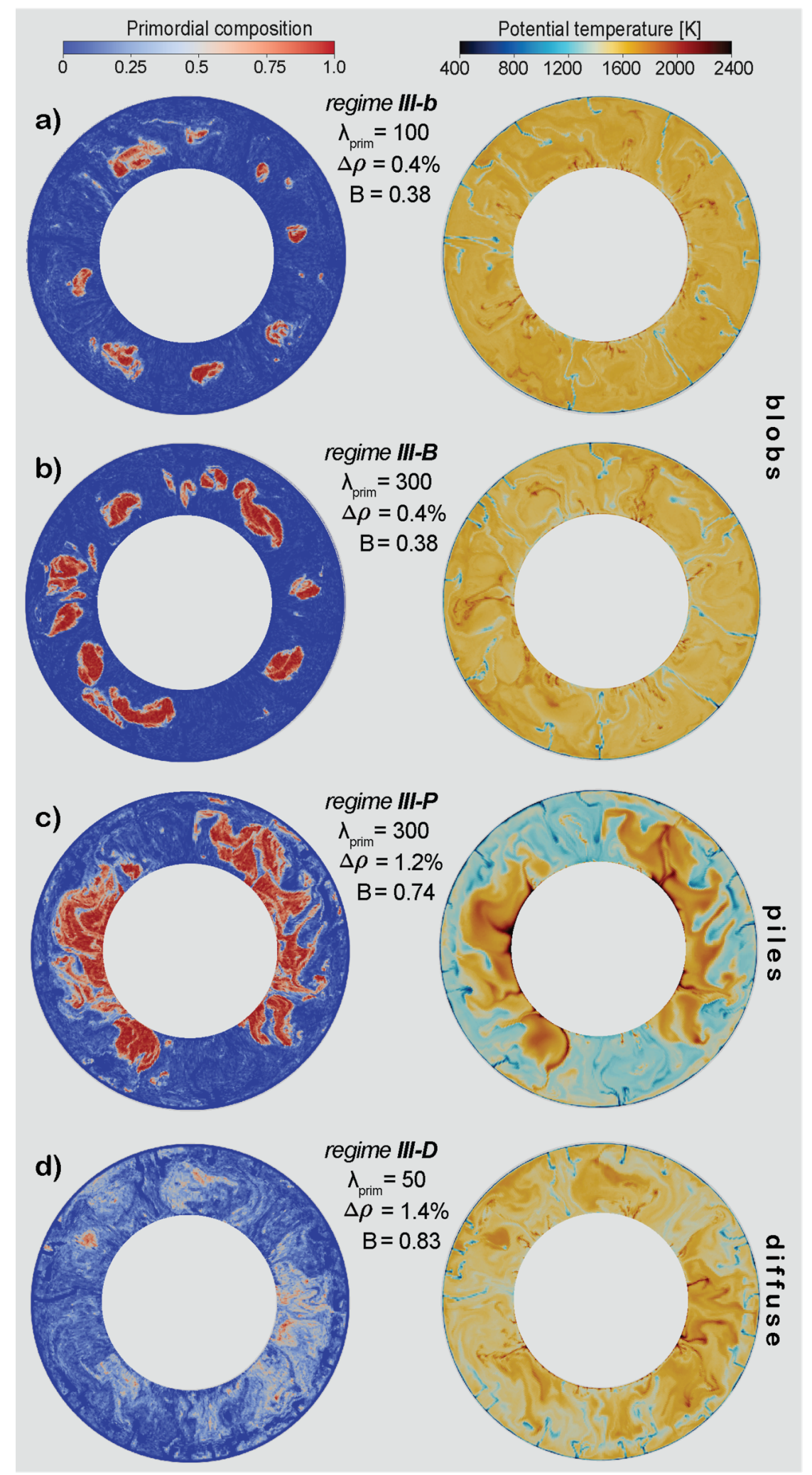

Figure 5 - Mantle sections of composition (red: primordial material; blue: harzburgite-basalt mechanical mixture) and potential temperature for all sub-regimes in regimes III at $\sim 4.5$ Gyr model time. For all cases shown, $K_{0, p r i m}=230 \mathrm{GPa} ; \lambda_{\text {prim, }}$ $\Delta \rho$ and $B$ as labelled. 
a) $\mathrm{K}_{0, \text { prim }}=225 \mathrm{GPa}$

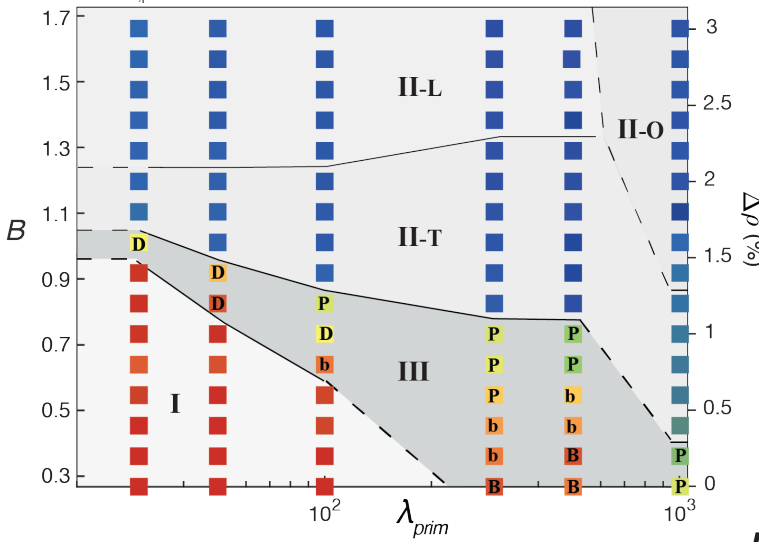

$N u_{\text {top }}$ b) $\mathrm{K}_{0, \mathrm{prim}}=230 \mathrm{GPa}$

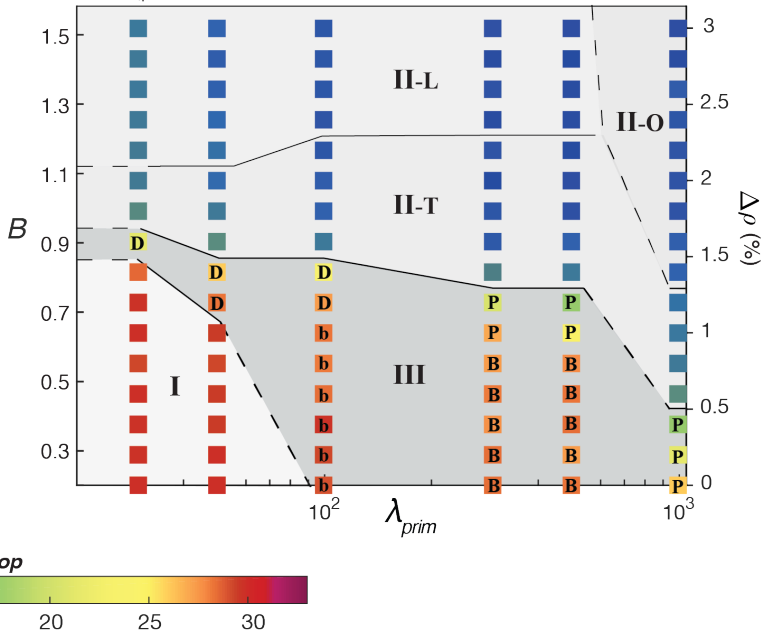

Figure 6 - Surface Nusselt numbers $\mathrm{N} u_{\text {top }}$ for all models, reported as average $\mathrm{Nu}$ top over 4.0-4.5 Gyr model time. $\mathrm{Nu}$ top is the ratio of convective heat transfer to conductive heat transfer for the top boundary. 


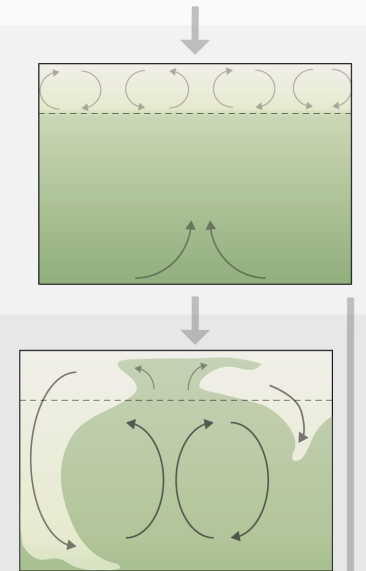

a) II-O: late overturn

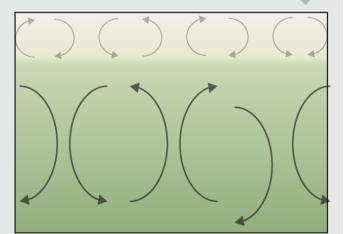

b) II-L: double-layered convection

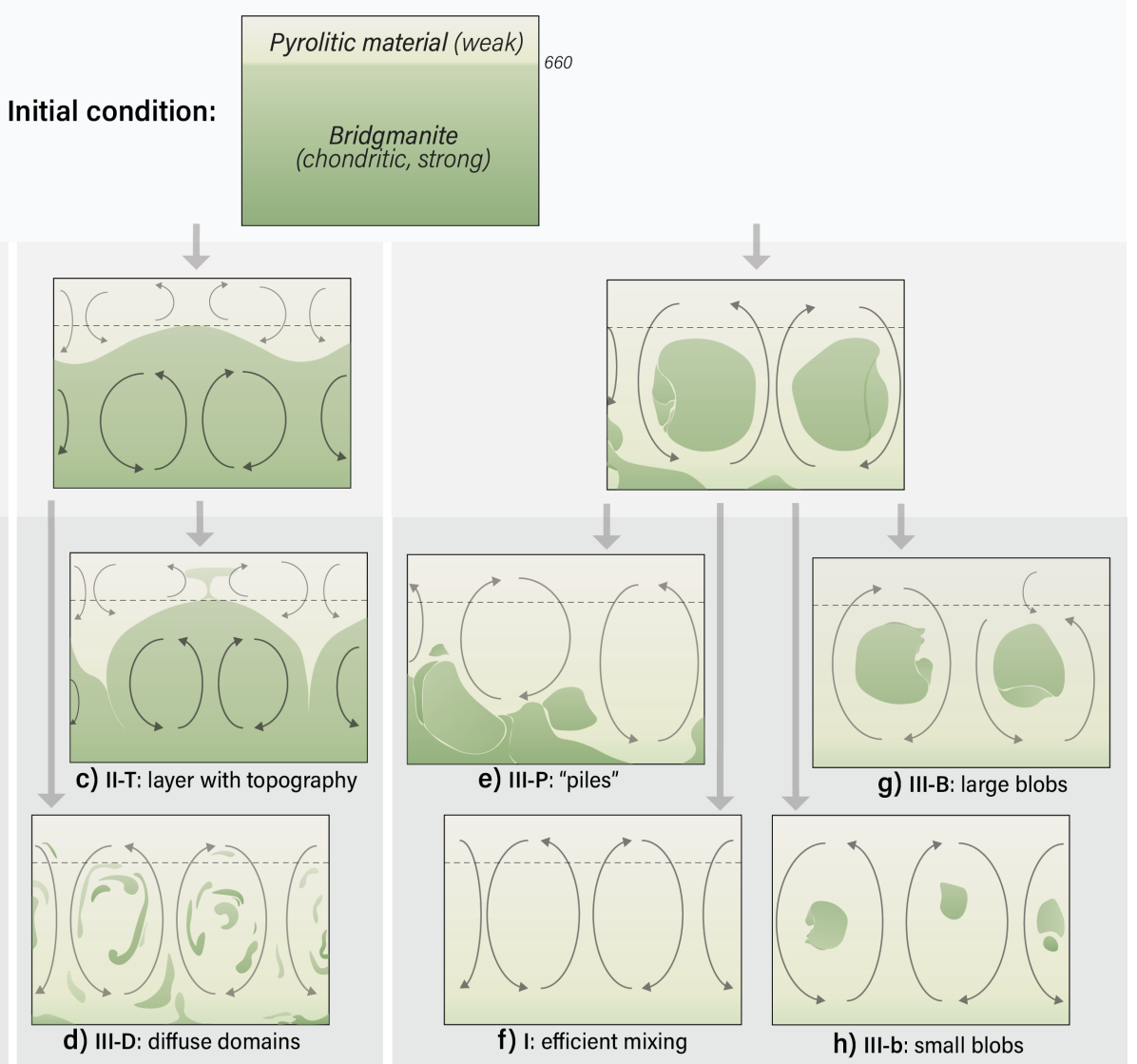

Figure 7-Summary figure with cartoons that depict mantle compositional structure and dynamic patterns for all regimes portrayed here (a-h), and how these regimes evolve ( $2^{\text {nd }}$ row) from the initial condition of our models ( $1^{\text {st }}$ row). For the discussion of the evolution of these regimes, the reader is referred to Section 3.1 in the text. 


\section{TABLES}

Table 1 - Physical properties used in the simulations of this study. LM = lower mantle; the asterisk * denotes that the parameters are systematically varied in this study. Since we solve for compressible convection, the adiabatic temperature, density, thermal conductivity, thermal expansivity, and heat capacity are pressure-dependent following a third-order BirchMurnaghan equation of state [Tackley et al., 2013].

\begin{tabular}{llll}
\hline Property & Symbol & Value & Units \\
\hline Mantle domain thickness & $D$ & 2890 & $\mathrm{~km}$ \\
Gravitational acceleration & $G$ & 9.81 & $\mathrm{~m} / \mathrm{s}^{3}$ \\
Surface temperature & $T_{\mathrm{S}}$ & 300 & $\mathrm{~K}$ \\
CMB temperature & $T_{\mathrm{CMB}}$ & 4000 & $\mathrm{~K}$ \\
Reference viscosity & $\eta_{0}$ & $1.2 \cdot 10^{21}$ & $\mathrm{~Pa} \cdot \mathrm{s}$ \\
Reference temperature & $T_{0}$ & 1600 & $\mathrm{~K}$ \\
Activation energy & $E_{\mathrm{a}}$ & 35.662 & $\mathrm{~kJ} / \mathrm{mol}$ \\
Activation volume & $V_{\mathrm{a}}$ & 0 & $\mathrm{~cm} / \mathrm{mol}$ \\
Yield stress & $\tau_{\text {yield }}$ & 20 & $\mathrm{MPa}$ \\
Yield stress depth derivative & $\tau_{\text {yield }}^{\prime}$ & 0.008 & $\mathrm{MPa} / \mathrm{MPa}$ \\
Surface specific heat capacity & $C_{\mathrm{p}}$ & 1200 & $\mathrm{~J} /(\mathrm{kg} \cdot \mathrm{K})$ \\
Surface thermal conductivity & $k$ & 3 & $\mathrm{~W} /(\mathrm{m} \cdot \mathrm{K})$ \\
Surface thermal expansivity & $\alpha_{0}$ & $3 \cdot 10^{-5}$ & $\mathrm{~K} \cdot{ }^{-1}$ \\
Post-perovskite viscosity contrast & $\lambda_{\mathrm{ppv}}$ & $10^{-3}$ & \\
Harzburgite - surface density & $\rho_{\mathrm{s}, \mathrm{Hz}}$ & 3200 & $\mathrm{~kg} / \mathrm{m}^{3}$ \\
Basalt - surface density & $\rho_{\mathrm{s}, \mathrm{BS}}$ & 3080 & $\mathrm{~kg} / \mathrm{m}^{3}$ \\
Primordial - surface density & $\rho_{\mathrm{S}, \text { prim }}$ & 3081 & $\mathrm{~kg} / \mathrm{m}^{3}$ \\
Primordial - LM viscosity contrast* & $\lambda_{\text {prim }}$ & $30-1000$ & \\
Primordial - density increase of $\rho_{\mathrm{s}, \mathrm{prim}}{ }^{*}$ & $\Delta \rho_{\text {prim }}$ & $0-92.43$ & $\mathrm{~kg} / \mathrm{m}^{3}$ \\
\hline
\end{tabular}


Table 2 - Phase change parameters used in this study for the olivine, pyroxene-garnet and primordial system (the latter is parametrised to fit the density profile of a mixture of $50 \%$ basalt and $50 \%$ harzburgite from Xu et al. (2008)). The table shows the depth and temperature at which a phase transition occurs; $\Delta \rho_{\mathrm{pc}}$ and $\gamma$ denote the density jump across the phase transition and the Clapeyron slope, respectively. For primordial material, we assume phase change depths and Clapeyron slopes similar as those for the pyroxene-garnet system, since mostly pyroxene-garnet is stabilised in bridgmanitic materials. Moreover, $\Delta \rho_{\mathrm{pc}}$ was chosen such that the density profile is consistent with that of a bridgmanitic material with a (Mg+Fe)/Si ratio of $\sim 1.0$ (see text). The Clapeyron slope for the post-perovskite phase change is similar to that used in previous numerical studies [e.g., Tackley et al., 2013). In the olivine system, the 410 and 660 phase changes are made discontinuous, whereas all other phase changes in all systems are defined as tangential functions that transition between the phases across a predefined phase loop width (see Figure 1). A phase change is discontinuous when the vertical resolution is larger than the width of the phase change. Finally, $\mathrm{K}_{0}$ refers to the reference bulk modulus for the system for each individual layer. The asterisk * denotes that the parameter is varied in this study.

\begin{tabular}{|c|c|c|c|c|c|}
\hline Depth (km) & Temperature (K) & $\Delta \rho_{\mathrm{pc}}\left(\mathrm{kg} / \mathrm{m}^{3}\right)$ & $\begin{array}{l}\text { phase change } \\
\text { width }[\mathrm{km}]\end{array}$ & $\gamma(\mathrm{MPa} / \mathrm{K})$ & $\mathrm{K}_{0}(\mathrm{GPa})$; depth range $(\mathrm{km})$ \\
\hline \multicolumn{5}{|c|}{ Olivine $\left(\rho_{\text {surf }}=3240 \mathrm{~kg} / \mathrm{m}^{3}\right)$} & $163(0-410)$ \\
\hline 410 & 1600 & 180 & discontinuous & +2.5 & $85(410-660)$ \\
\hline 660 & 1900 & 435 & discontinuous & $-2,5$ & $210(660-2740)$ \\
\hline 2740 & 2300 & 61.6 & 25 & +10 & $210 \quad(2740-2890)$ \\
\hline \multicolumn{5}{|c|}{ Pyroxene-garnet $\left(\rho_{\text {surf }}=3080 \mathrm{~kg} / \mathrm{m}^{3}\right)$} & $163(0-40)$ \\
\hline 40 & 1000 & 350 & 25 & 0 & $130(40-300)$ \\
\hline 300 & 1600 & 100 & 75 & 1.0 & $85 \quad(300-720)$ \\
\hline 720 & 1900 & 350 & 75 & 1.0 & $210(720-2740)$ \\
\hline 2740 & 2300 & 61.6 & 25 & +10 & $210(2740-2890)$ \\
\hline \multicolumn{5}{|c|}{ Primordial material $\left(\rho_{\text {surf }}=3081 \mathrm{~kg} / \mathrm{m}^{3}\right)$} & $163(0-60)$ \\
\hline 60 & 1000 & 280 & 25 & 0 & $130(60-300)$ \\
\hline 300 & 1600 & 120 & 75 & 1.0 & $85(300-720)$ \\
\hline 720 & 1900 & 450 & 75 & 1.0 & $225 / 230 * \quad(720-2740)$ \\
\hline 2740 & 2300 & 61.6 & 25 & +10 & $210(2740-2890)$ \\
\hline
\end{tabular}


826

827

828

829

830

\section{SUPPLEMENTARY MATERIAL}

\section{SUPPLEMENTARY FIGURES}

a) Viscosity

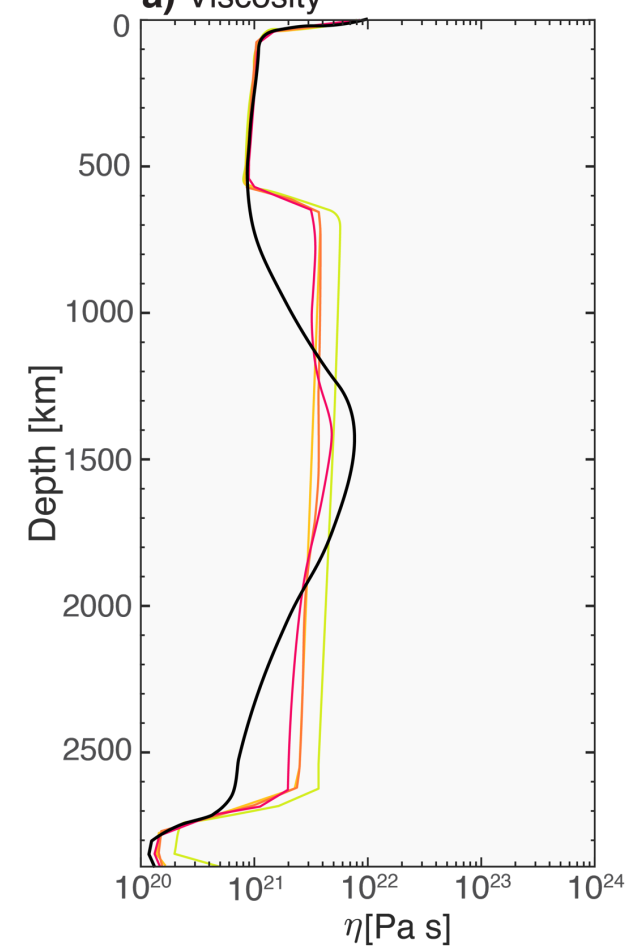

b) Primordial fraction

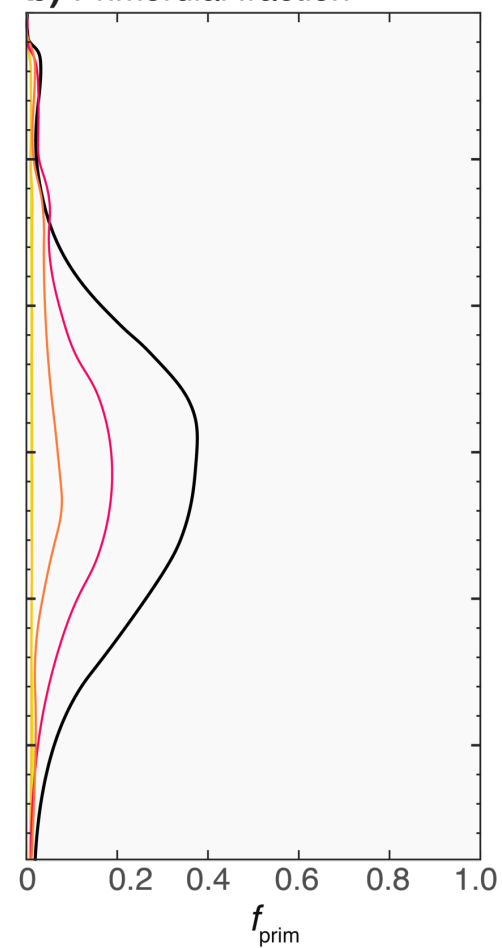

M30d04660 (Regime III-B; $K_{0, \text { prim }}=230 \mathrm{GPa}, \lambda_{\text {prim }}=300, \lambda_{600}=0, \Delta \rho_{\text {prim }}=0.4 \%$ )

M30c04660 (K $\left.\mathrm{K}_{0 \text { prim }}=230 \mathrm{GPa}, \lambda_{\text {prim }}=100, \lambda_{\text {660 }}=3.0, \Delta \mathrm{\rho}_{\text {prim }}=0.4 \%\right)$

M30b04660 ( $\mathrm{K}_{0, \mathrm{prim}}=230 \mathrm{GPa}, \lambda_{\text {prim }}=50, \lambda_{\text {b60 }}=11.6, \Delta \rho_{\text {prim }}=0.4 \%$

M30a04660 $\left(\mathrm{K}_{0, \text { prim }}=230 \mathrm{GPa}, \lambda_{\text {prim }}=30, \lambda_{\text {bøo }}=12, \Delta \rho_{\text {pim }}=0.4 \%\right)$

M30f0 $660\left(\mathrm{~K}_{0, \text { prim }}=230 \mathrm{GPa}, \lambda_{\text {prim }}=1, \lambda_{660}=120, \Delta \rho_{\text {prim }}=0.4 \%\right)$

Supplementary Figure S.1- Averaged radial profiles of a) viscosity and b) primordial fraction for the reference model (in black, displaying BEAMS as described by Ballmer et al., 2017) and various $\lambda_{660}$ test cases (see Section 3.2 and Supplementary Table 1). The test cases have an additional viscosity jump $\lambda_{660}$ at $660 \mathrm{~km}$ depth such that the final viscosity profile is more similar to that of the reference case (black line), shown in (a). Adding these additional viscosity steps does not lead to BEAMSlike formation (no increase in viscosity or primordial hill in the mid mantle). Therefore, composition-dependent viscosity is a critical ingredient to promote BEAMS-like heterogeneity preservation. The radial profiles are linearly averaged spatially as well as over time (between model times 4.0 and $4.5 \mathrm{Ga}$ ). 
839

840

841

\section{SUPPLEMENTARY TABLES}

Supplementary Table 1 - summary of conditions and results of all conducted numerical experiments. All models have a resolution of $512 \times 64$ grid points and an average of 30 tracers per cell, unless stated otherwise: ${ }^{11} 512 \times 64$ grid points, 45 tracers per cell; ${ }^{2} 512 \times 128$ grid points, 25 tracers per cell; ${ }^{R 4} 1028 \times 128$ grid points, 20 tracers per cell. $K_{0, p r i m}$ is the bulk modulus in the lower mantle of primordial material; $\lambda_{\text {prim }}$ is the viscosity contrast between primordial and pyrolitic material in the lower mantle; $\Delta \rho_{\text {prim }}$ is the shift in density of primordial material compared to its reference profile; $B_{2000}$ is the initial buoyancy number taken at $2000 \mathrm{~km}$ depth (see Methods); $\lambda_{660}$ is the additional viscosity jump at $660 \mathrm{~km}$ depth; $N u_{\text {top }}$ is the surface Nusselt number; and the final percentage of primordial material preserved is calculated at 4.5 Gyr of model evolution time. Regime l: efficient mixing and whole-mantle convection; regime II: inefficient mixing and variable styles of doublelayered convection, i.e., with or without topography (II-T or II-L) or due to very delayed overturn (II-O); regime III: partial heterogeneity preservation as diffuse domains (III-D), marginally stable piles (III-P) or small-to-large mid-mantle blobs (b/B). 


\begin{tabular}{|c|c|c|c|c|c|c|c|c|}
\hline Model & $\begin{array}{l}\boldsymbol{K}_{0, \text { prim }} \\
{[\mathrm{GPa}]}\end{array}$ & $\lambda_{\text {prim }}$ & $\begin{array}{c}\Delta \rho_{\text {prim }} \\
{[\%]}\end{array}$ & $B_{2000}$ & $\lambda_{660}$ & $N u_{\text {top }}$ & $\begin{array}{c}\text { Primordial material } \\
\text { preserved } \\
{[\%]}\end{array}$ & Regime \\
\hline $\mathrm{M} 25 \mathrm{aO0}$ & 225 & 30 & 0 & 0.29 & 1 & 29.7 & 4.1 & 1 \\
\hline $\mathrm{M} 25 \mathrm{aO} 2$ & 225 & 30 & 0.2 & 0.38 & 1 & 30.6 & 5.2 & 1 \\
\hline $\mathrm{M} 25 \mathrm{a} 04$ & 225 & 30 & 0.4 & 0.47 & 1 & 31.4 & 3.5 & I \\
\hline $\mathrm{M} 25 \mathrm{a} 06$ & 225 & 30 & 0.6 & 0.56 & 1 & 30.2 & 6.9 & 1 \\
\hline $\mathrm{M} 25 \mathrm{a} 08$ & 225 & 30 & 0.8 & 0.65 & 1 & 27.6 & 6.4 & 1 \\
\hline M25a10 & 225 & 30 & 1.0 & 0.74 & 1 & 29.8 & 10.7 & I \\
\hline M25a12 & 225 & 30 & 1.2 & 0.83 & 1 & 30.1 & 9.5 & I \\
\hline M25a14 & 225 & 30 & 1.4 & 0.92 & 1 & 28.4 & 15.6 & I \\
\hline M25a16 & 225 & 30 & 1.6 & 1.01 & 1 & 24.8 & 61.2 & III-D \\
\hline M25a18 & 225 & 30 & 1.8 & 1.10 & 1 & 9.6 & 77.9 & II-T \\
\hline M25a20 & 225 & 30 & 2.0 & 1.19 & 1 & 8.7 & 85.4 & II-T \\
\hline M25a22 & 225 & 30 & 2.2 & 1.28 & 1 & 9.2 & 88.7 & $\mathrm{II}-\mathrm{L}$ \\
\hline M25a24 & 225 & 30 & 2.4 & 1.37 & 1 & 8.6 & 92.1 & II-L \\
\hline M25a26 & 225 & 30 & 2.6 & 1.46 & 1 & 8.5 & 96.5 & II-L \\
\hline M25a28 & 225 & 30 & 2.8 & 1.55 & 1 & 8.5 & 94.3 & II-L \\
\hline M25a30 & 225 & 30 & 3.0 & 1.64 & 1 & 8.8 & 95.9 & II-L \\
\hline $\mathrm{M} 25 \mathrm{~b} 00$ & 225 & 50 & 0 & 0.29 & 1 & 30.8 & 7.5 & I \\
\hline $\mathrm{M} 25 \mathrm{~b} 02$ & 225 & 50 & 0.2 & 0.38 & 1 & 30.5 & 9.2 & I \\
\hline M25b04 & 225 & 50 & 0.4 & 0.47 & 1 & 30.6 & 2.8 & I \\
\hline M25b06 & 225 & 50 & 0.6 & 0.56 & 1 & 29.7 & 10.2 & I \\
\hline M25b08 & 225 & 50 & 0.8 & 0.65 & 1 & 28.4 & 9.3 & I \\
\hline M25b10 & 225 & 50 & 1.0 & 0.74 & 1 & 29.6 & 14.1 & 1 \\
\hline$M 25 b 12$ & 225 & 50 & 1.2 & 0.83 & 1 & 28.3 & 20.7 & III-D \\
\hline M25b14 & 225 & 50 & 1.4 & 0.92 & 1 & 27.4 & 27.5 & III-D \\
\hline M25b16 & 225 & 50 & 1.6 & 1.01 & 1 & 10.0 & 68.0 & II-T \\
\hline$M 25 b 18$ & 225 & 50 & 1.8 & 1.10 & 1 & 9.1 & 77.9 & II-T \\
\hline M25b20 & 225 & 50 & 2.0 & 1.19 & 1 & 9.1 & 89.6 & II-T \\
\hline$M 25 b 22$ & 225 & 50 & 2.2 & 1.28 & 1 & 8.5 & 91.4 & II-L \\
\hline M25b24 & 225 & 50 & 2.4 & 1.37 & 1 & 8.2 & 93.8 & II-L \\
\hline$M 25 b 26$ & 225 & 50 & 2.6 & 1.46 & 1 & 8.0 & 94.0 & II-L \\
\hline M25b28 & 225 & 50 & 2.8 & 1.55 & 1 & 8.0 & 95.5 & II-L \\
\hline$M 25 b 30$ & 225 & 50 & 3.0 & 1.64 & 1 & 8.3 & 95.1 & II-L \\
\hline $\mathrm{M} 25 \mathrm{c} 00$ & 225 & 100 & 0 & 0.29 & 1 & 29.6 & 4.6 & 1 \\
\hline $\mathrm{M} 25 \mathrm{c0} 2$ & 225 & 100 & 0.2 & 0.38 & 1 & 29.0 & 3.7 & 1 \\
\hline $\mathrm{M} 25 \mathrm{c04}$ & 225 & 100 & 0.4 & 0.47 & 1 & 29.4 & 5.0 & 1 \\
\hline $\mathrm{M} 25 \mathrm{c06}$ & 225 & 100 & 0.6 & 0.56 & 1 & 29.9 & 9.3 & 1 \\
\hline $\mathrm{M} 25 \mathrm{c08}$ & 225 & 100 & 0.8 & 0.65 & 1 & 28.0 & 12.1 & III-b \\
\hline $\mathrm{M} 25 \mathrm{c} 10$ & 225 & 100 & 1.0 & 0.74 & 1 & 22.6 & 19.7 & III-D \\
\hline$M 25 c 12$ & 225 & 100 & 1.2 & 0.83 & 1 & 18.5 & 24.7 & III-P \\
\hline M25c14 & 225 & 100 & 1.4 & 0.92 & 1 & 8.2 & 66.2 & II-T \\
\hline $\mathrm{M} 25 \mathrm{c} 16$ & 225 & 100 & 1.6 & 1.01 & 1 & 7.4 & 76.4 & II-T \\
\hline$M 25 c 18$ & 225 & 100 & 1.8 & 1.10 & 1 & 7.5 & 87.4 & II-T \\
\hline$M 25 c 20$ & 225 & 100 & 2.0 & 1.19 & 1 & 7.2 & 88.9 & II-T \\
\hline$M 25 c 22$ & 225 & 100 & 2.2 & 1.28 & 1 & 7.0 & 93.1 & II-L \\
\hline$M 25 c 24$ & 225 & 100 & 2.4 & 1.37 & 1 & 7.0 & 92.0 & II-L \\
\hline
\end{tabular}




\begin{tabular}{|c|c|c|c|c|c|c|c|c|}
\hline M25c26 & 225 & 100 & 2.6 & 1.46 & 1 & 6.9 & 91.8 & II-L \\
\hline $\mathrm{M} 25 \mathrm{c} 28$ & 225 & 100 & 2.8 & 1.55 & 1 & 7.4 & 84.8 & II-L \\
\hline$M 25 c 30$ & 225 & 100 & 3.0 & 1.64 & 1 & 7.4 & 96.7 & II-L \\
\hline $\mathrm{M} 25 \mathrm{~d} 00$ & 225 & 300 & 0 & 0.29 & 1 & 28.3 & 20.0 & III-B \\
\hline $\mathrm{M} 25 \mathrm{~d} 02$ & 225 & 300 & 0.2 & 0.38 & 1 & 27.9 & 30.1 & III-b \\
\hline $\mathrm{M} 25 \mathrm{~d} 04$ & 225 & 300 & 0.4 & 0.47 & 1 & 27.0 & 27.4 & III-b \\
\hline M25d06 & 225 & 300 & 0.6 & 0.56 & 1 & 26.4 & 32.2 & III-P \\
\hline $\mathrm{M} 25 \mathrm{~d} 08$ & 225 & 300 & 0.8 & 0.65 & 1 & 20.8 & 52.3 & III-P \\
\hline $\mathrm{M} 25 \mathrm{~d} 10$ & 225 & 300 & 1.0 & 0.74 & 1 & 19.5 & 61.0 & III-P \\
\hline$M 25 d 12$ & 225 & 300 & 1.2 & 0.83 & 1 & 7.8 & 63.8 & II-T \\
\hline $\mathrm{M} 25 \mathrm{~d} 14$ & 225 & 300 & 1.4 & 0.92 & 1 & 7.3 & 75.2 & II-T \\
\hline M25d16 & 225 & 300 & 1.6 & 1.01 & 1 & 6.9 & 78.8 & II-T \\
\hline $\mathrm{M} 25 \mathrm{~d} 18$ & 225 & 300 & 1.8 & 1.10 & 1 & 6.3 & 84.2 & II-T \\
\hline $\mathrm{M} 25 \mathrm{~d} 20$ & 225 & 300 & 2.0 & 1.19 & 1 & 5.5 & 89.5 & II-T \\
\hline $\mathrm{M} 25 \mathrm{~d} 22$ & 225 & 300 & 2.2 & 1.28 & 1 & 5.8 & 89.0 & II-T \\
\hline$M 25 d 24$ & 225 & 300 & 2.4 & 1.37 & 1 & 5.7 & 94.5 & II-L \\
\hline $\mathrm{M} 25 \mathrm{~d} 26$ & 225 & 300 & 2.6 & 1.46 & 1 & 5.6 & 93.1 & II-L \\
\hline $\mathrm{M} 25 \mathrm{~d} 28$ & 225 & 300 & 2.8 & 1.55 & 1 & 5.6 & 98.0 & II-L \\
\hline$M 25 d 30$ & 225 & 300 & 3.0 & 1.64 & 1 & 5.2 & 99.5 & II-L \\
\hline $\mathrm{M} 25 \mathrm{e} 00$ & 225 & 500 & 0 & 0.29 & 1 & 27.7 & 33.0 & III-B \\
\hline $\mathrm{M} 25 \mathrm{e} 02$ & 225 & 500 & 0.2 & 0.38 & 1 & 28.8 & 30.2 & III-B \\
\hline $\mathrm{M} 25 \mathrm{e} 04$ & 225 & 500 & 0.4 & 0.47 & 1 & 26.3 & 38.8 & III-b \\
\hline M25e06 & 225 & 500 & 0.6 & 0.56 & 1 & 25.8 & 47.0 & III-b \\
\hline M25e08 & 225 & 500 & 0.8 & 0.65 & 1 & 15.7 & 57.1 & III-P \\
\hline M25e10 & 225 & 500 & 1.0 & 0.74 & 1 & 15.2 & 51.3 & III-P \\
\hline M25e12 & 225 & 500 & 1.2 & 0.83 & 1 & 7.1 & 69.4 & II-T \\
\hline M25e14 & 225 & 500 & 1.4 & 0.92 & 1 & 5.6 & 71.1 & II-T \\
\hline M25e16 & 225 & 500 & 1.6 & 1.01 & 1 & 5.9 & 92.0 & II-T \\
\hline M25e18 & 225 & 500 & 1.8 & 1.10 & 1 & 5.2 & 89.3 & II-T \\
\hline$M 25 e 20$ & 225 & 500 & 2.0 & 1.19 & 1 & 5.4 & 93.3 & II-T \\
\hline M25e22 & 225 & 500 & 2.2 & 1.28 & 1 & 5.4 & 91.4 & II-T \\
\hline M25e24 & 225 & 500 & 2.4 & 1.37 & 1 & 4.8 & 94.8 & II-L \\
\hline M25e26 & 225 & 500 & 2.6 & 1.46 & 1 & 5.3 & 95.4 & II-L \\
\hline M25e28 & 225 & 500 & 2.8 & 1.55 & 1 & 5.0 & 97.5 & II-L \\
\hline M25e30 & 225 & 500 & 3.0 & 1.64 & 1 & 4.8 & 99.8 & II-L \\
\hline$M 25 f 00$ & 225 & 1000 & 0 & 0.29 & 1 & 18.7 & 68.2 & III-P \\
\hline$M 25 f 02$ & 225 & 1000 & 0.2 & 0.38 & 1 & 14.8 & 74.2 & III-P \\
\hline M25f04 & 225 & 1000 & 0.4 & 0.47 & 1 & 13.6 & 73.8 & II-T \\
\hline$M 25 f 06$ & 225 & 1000 & 0.6 & 0.56 & 1 & 11.6 & 80.1 & II-T \\
\hline$M 25 f 08$ & 225 & 1000 & 0.8 & 0.65 & 1 & 11.0 & 86.2 & II-T \\
\hline$M 25 f 10$ & 225 & 1000 & 1.0 & 0.74 & 1 & 10.4 & 89.1 & II-T \\
\hline$M 25 f 12$ & 225 & 1000 & 1.2 & 0.83 & 1 & 10.8 & 91.7 & II-T \\
\hline$M 25 f 14$ & 225 & 1000 & 1.4 & 0.92 & 1 & 9.2 & 95.0 & II-O \\
\hline$M 25 f 16$ & 225 & 1000 & 1.6 & 1.01 & 1 & 6.2 & 93.9 & II-O \\
\hline$M 25 f 18$ & 225 & 1000 & 1.8 & 1.10 & 1 & 7.0 & 98.3 & II-O \\
\hline$M 25 f 20$ & 225 & 1000 & 2.0 & 1.19 & 1 & 6.3 & 95.7 & II-O \\
\hline$M 25 f 22$ & 225 & 1000 & 2.2 & 1.28 & 1 & 5.5 & 97.8 & II-O \\
\hline$M 25 f 24$ & 225 & 1000 & 2.4 & 1.37 & 1 & 4.6 & 99.3 & II-O \\
\hline$M 25 f 26$ & 225 & 1000 & 2.6 & 1.46 & 1 & 6.3 & 99.7 & II-O \\
\hline
\end{tabular}




\begin{tabular}{|c|c|c|c|c|c|c|c|c|}
\hline$M 25 f 28$ & 225 & 1000 & 2.8 & 1.55 & 1 & 5.2 & 99.6 & II-O \\
\hline$M 25 f 30$ & 225 & 1000 & 3.0 & 1.64 & 1 & 5.5 & 99.8 & II-O \\
\hline M30a00 & 230 & 30 & 0 & 0.20 & 1 & 30.7 & 4.0 & I \\
\hline M30a02 & 230 & 30 & 0.2 & 0.29 & 1 & 30.2 & 3.7 & I \\
\hline M30a04 & 230 & 30 & 0.4 & 0.38 & 1 & 29.6 & 3.9 & 1 \\
\hline M30a06 & 230 & 30 & 0.6 & 0.47 & 1 & 30.2 & 5.3 & 1 \\
\hline M30a08 & 230 & 30 & 0.8 & 0.56 & 1 & 28.9 & 10.3 & 1 \\
\hline M30a10 & 230 & 30 & 1.0 & 0.65 & 1 & 29.5 & 17.7 & I \\
\hline M30a12 & 230 & 30 & 1.2 & 0.74 & 1 & 29.7 & 15.4 & 1 \\
\hline M30a14 & 230 & 30 & 1.4 & 0.83 & 1 & 28.0 & 19.9 & 1 \\
\hline M30a16 & 230 & 30 & 1.6 & 0.92 & 1 & 19.9 & 49.8 & III-D \\
\hline M30a18 & 230 & 30 & 1.8 & 1.01 & 1 & 12.0 & 73.1 & II-T \\
\hline M30a20 & 230 & 30 & 2.0 & 1.10 & 1 & 11.7 & 79.7 & II-T \\
\hline M30a22 & 230 & 30 & 2.2 & 1.19 & 1 & 12.2 & 88.3 & II-L \\
\hline M30a24 & 230 & 30 & 2.4 & 1.27 & 1 & 11.5 & 92.2 & II-L \\
\hline M30a26 & 230 & 30 & 2.6 & 1.36 & 1 & 11.3 & 92.8 & II-L \\
\hline M30a28 & 230 & 30 & 2.8 & 1.45 & 1 & 11.3 & 94.0 & II-L \\
\hline M30а30 & 230 & 30 & 3.0 & 1.54 & 1 & 11.5 & 94.7 & II-L \\
\hline M30b00 & 230 & 50 & 0 & 0.20 & 1 & 29.6 & 4.4 & 1 \\
\hline M30b02 & 230 & 50 & 0.2 & 0.29 & 1 & 29.4 & 8.3 & I \\
\hline M30b04 & 230 & 50 & 0.4 & 0.38 & 1 & 30.0 & 8.0 & 1 \\
\hline M30b06 & 230 & 50 & 0.6 & 0.47 & 1 & 28.8 & 7.0 & 1 \\
\hline M30b08 & 230 & 50 & 0.8 & 0.56 & 1 & 27.8 & 9.1 & I \\
\hline M30b10 & 230 & 50 & 1.0 & 0.65 & 1 & 28.9 & 13.0 & 1 \\
\hline M30b12 & 230 & 50 & 1.2 & 0.74 & 1 & 29.4 & 21.7 & III-D \\
\hline M30b14 & 230 & 50 & 1.4 & 0.83 & 1 & 27.3 & 33.6 & III-D \\
\hline M30b16 & 230 & 50 & 1.6 & 0.92 & 1 & 19.5 & 71.1 & II-T \\
\hline M30b18 & 230 & 50 & 1.8 & 1.01 & 1 & 12.2 & 83.0 & II-T \\
\hline M30b20 & 230 & 50 & 2.0 & 1.10 & 1 & 10.4 & 87.9 & II-T \\
\hline M30b22 & 230 & 50 & 2.2 & 1.19 & 1 & 10.0 & 88.0 & II-L \\
\hline M30b24 & 230 & 50 & 2.4 & 1.27 & 1 & 9.3 & 93.9 & II-L \\
\hline M30b26 & 230 & 50 & 2.6 & 1.36 & 1 & 9.2 & 93.3 & II-L \\
\hline M30b28 & 230 & 50 & 2.8 & 1.45 & 1 & 8.9 & 95.5 & II-L \\
\hline M30b30 & 230 & 50 & 3.0 & 1.54 & 1 & 8.6 & 95.2 & II-L \\
\hline M30c00 & 230 & 100 & 0 & 0.20 & 1 & 28.9 & 18.9 & III-b \\
\hline M30c02 & 230 & 100 & 0.2 & 0.29 & 1 & 28.4 & 20.1 & III-b \\
\hline M30c04 & 230 & 100 & 0.4 & 0.38 & 1 & 30.0 & 19.5 & III-b \\
\hline M30c06 & 230 & 100 & 0.6 & 0.47 & 1 & 27.9 & 24.3 & III-b \\
\hline M30c08 & 230 & 100 & 0.8 & 0.56 & 1 & 27.8 & 25.4 & III-b \\
\hline M30c10 & 230 & 100 & 1.0 & 0.65 & 1 & 27.4 & 26.1 & III-b \\
\hline M30c12 & 230 & 100 & 1.2 & 0.74 & 1 & 26.8 & 28.6 & III-D \\
\hline M30c14 & 230 & 100 & 1.4 & 0.83 & 1 & 21.2 & 40.8 & III-D \\
\hline M30c16 & 230 & 100 & 1.6 & 0.92 & 1 & 10.5 & 73.5 & II-T \\
\hline M30c18 & 230 & 100 & 1.8 & 1.01 & 1 & 8.6 & 82.7 & II-T \\
\hline M30c20 & 230 & 100 & 2.0 & 1.10 & 1 & 8.5 & 88.9 & II-T \\
\hline M30c22 & 230 & 100 & 2.2 & 1.19 & 1 & 7.8 & 93.8 & II-T \\
\hline M30c24 & 230 & 100 & 2.4 & 1.27 & 1 & 7.5 & 93.0 & II-L \\
\hline M30c26 & 230 & 100 & 2.6 & 1.36 & 1 & 7.4 & 94.8 & II-L \\
\hline
\end{tabular}




\begin{tabular}{|c|c|c|c|c|c|c|c|c|}
\hline M30c28 & 230 & 100 & 2.8 & 1.45 & 1 & 7.3 & 96.6 & II-L \\
\hline M30c30 & 230 & 100 & 3.0 & 1.54 & 1 & 7.0 & 96.0 & II-L \\
\hline M30d00 & 230 & 300 & 0 & 0.20 & 1 & 28.3 & 28.6 & III-B \\
\hline M30d02 & 230 & 300 & 0.2 & 0.29 & 1 & 28.7 & 30.2 & III-B \\
\hline M30d04 & 230 & 300 & 0.4 & 0.38 & 1 & 27.5 & 29.8 & III-B \\
\hline M30d06 & 230 & 300 & 0.6 & 0.47 & 1 & 28.0 & 34.0 & III-B \\
\hline M30d08 & 230 & 300 & 0.8 & 0.56 & 1 & 26.9 & 42.0 & III-B \\
\hline M30d10 & 230 & 300 & 1.0 & 0.65 & 1 & 26.6 & 48.8 & III-P \\
\hline M30d12 & 230 & 300 & 1.2 & 0.74 & 1 & 19.2 & 62.1 & III-P \\
\hline M30d14 & 230 & 300 & 1.4 & 0.83 & 1 & 11.1 & 68.8 & II-T \\
\hline M30d16 & 230 & 300 & 1.6 & 0.92 & 1 & 8.0 & 76.3 & II-T \\
\hline M30d18 & 230 & 300 & 1.8 & 1.01 & 1 & 7.7 & 87.0 & II-T \\
\hline M30d20 & 230 & 300 & 2.0 & 1.10 & 1 & 5.8 & 86.6 & II-T \\
\hline M30d22 & 230 & 300 & 2.2 & 1.19 & 1 & 6.6 & 89.2 & II-T \\
\hline $\mathrm{M} 30 \mathrm{~d} 24$ & 230 & 300 & 2.4 & 1.27 & 1 & 5.3 & 93.8 & II-L \\
\hline M30d26 & 230 & 300 & 2.6 & 1.36 & 1 & 5.2 & 95.1 & $\mathrm{II}-\mathrm{L}$ \\
\hline M30d28 & 230 & 300 & 2.8 & 1.45 & 1 & 5.5 & 96.0 & II-L \\
\hline $\mathrm{M} 30 \mathrm{~d} 30$ & 230 & 300 & 3.0 & 1.54 & 1 & 5.0 & 98.9 & II-L \\
\hline $\mathrm{M} 30 \mathrm{e} 00$ & 230 & 500 & 0 & 0.20 & 1 & 28.2 & 33.9 & III-B \\
\hline $\mathrm{M} 30 \mathrm{e} 02$ & 230 & 500 & 0.2 & 0.29 & 1 & 27.2 & 35.3 & III-B \\
\hline $\mathrm{M} 30 \mathrm{e} 04$ & 230 & 500 & 0.4 & 0.38 & 1 & 28.6 & 34.8 & III-B \\
\hline M30e06 & 230 & 500 & 0.6 & 0.47 & 1 & 28.5 & 38.0 & III-B \\
\hline $\mathrm{M} 30 \mathrm{e} 08$ & 230 & 500 & 0.8 & 0.56 & 1 & 27.9 & 43.0 & III-B \\
\hline M30e10 & 230 & 500 & 1.0 & 0.65 & 1 & 24.2 & 49.2 & III-P \\
\hline M30e12 & 230 & 500 & 1.2 & 0.74 & 1 & 16.4 & 65.4 & III-P \\
\hline M30e14 & 230 & 500 & 1.4 & 0.83 & 1 & 10.5 & 69.3 & II-T \\
\hline M30e16 & 230 & 500 & 1.6 & 0.92 & 1 & 5.6 & 71.2 & II-T \\
\hline M30e18 & 230 & 500 & 1.8 & 1.01 & 1 & 5.1 & 74.1 & II-T \\
\hline M30e20 & 230 & 500 & 2.0 & 1.10 & 1 & 4.8 & 88.8 & II-T \\
\hline M30e22 & 230 & 500 & 2.2 & 1.19 & 1 & 4.4 & 89.2 & II-T \\
\hline M30e24 & 230 & 500 & 2.4 & 1.27 & 1 & 5.5 & 91.2 & II-L \\
\hline M30e26 & 230 & 500 & 2.6 & 1.36 & 1 & 5.2 & 94.7 & II-L \\
\hline M30e28 & 230 & 500 & 2.8 & 1.45 & 1 & 4.9 & 97.8 & II-L \\
\hline M30e30 & 230 & 500 & 3.0 & 1.54 & 1 & 4.8 & 99.2 & II-L \\
\hline M30f00 & 230 & 1000 & 0 & 0.20 & 1 & 25.9 & 62.3 & III-B \\
\hline M30f02 & 230 & 1000 & 0.2 & 0.29 & 1 & 23.5 & 67.0 & III-P \\
\hline M30f04 & 230 & 1000 & 0.4 & 0.38 & 1 & 16.6 & 69.2 & III-P \\
\hline M30f06 & 230 & 1000 & 0.6 & 0.47 & 1 & 11.5 & 70.8 & II-T \\
\hline M30f08 & 230 & 1000 & 0.8 & 0.56 & 1 & 11.1 & 75.1 & II-T \\
\hline M30f10 & 230 & 1000 & 1.0 & 0.65 & 1 & 10.3 & 86.4 & II-T \\
\hline M30f12 & 230 & 1000 & 1.2 & 0.74 & 1 & 10.0 & 90.7 & II-T \\
\hline M30f14 & 230 & 1000 & 1.4 & 0.83 & 1 & 9.2 & 93.9 & II-O \\
\hline M30f16 & 230 & 1000 & 1.6 & 0.92 & 1 & 8.5 & 95.8 & II-O \\
\hline M30f18 & 230 & 1000 & 1.8 & 1.01 & 1 & 6.9 & 95.0 & II-O \\
\hline M30f20 & 230 & 1000 & 2.0 & 1.10 & 1 & 7.5 & 96.6 & II-O \\
\hline M30f22 & 230 & 1000 & 2.2 & 1.19 & 1 & 5.5 & 98.8 & II-O \\
\hline M30f24 & 230 & 1000 & 2.4 & 1.27 & 1 & 6.6 & 98.5 & II-O \\
\hline M30f26 & 230 & 1000 & 2.6 & 1.36 & 1 & 5.9 & 99.0 & $\mathrm{II}-\mathrm{O}$ \\
\hline M30f28 & 230 & 1000 & 2.8 & 1.45 & 1 & 6.3 & 98.7 & II-O \\
\hline
\end{tabular}


Accepted manuscript for Earth and Planetary Science Letters, 2020

\begin{tabular}{|c|c|c|c|c|c|c|c|c|}
\hline M30f30 & 230 & 1000 & 3.0 & 1.54 & 1 & 5.4 & 99.4 & II-O \\
\hline $\mathrm{M} 30 \mathrm{a} 04^{\mathrm{R} 1}$ & 230 & 30 & 0.4 & 0.38 & 1 & 30.3 & 2.2 & I \\
\hline $\mathrm{M} 30 \mathrm{a} 04^{\mathrm{R} 2}$ & 230 & 30 & 0.4 & 0.38 & 1 & 30.7 & 1.9 & I \\
\hline M30c04 R1 & 230 & 100 & 0.4 & 0.38 & 1 & 29.6 & 21.3 & III-b \\
\hline $\mathrm{M} 30 \mathrm{c04}$ R2 & 230 & 100 & 0.4 & 0.38 & 1 & 29.2 & 23.0 & III-b \\
\hline $\mathrm{M} 30 \mathrm{c0} 4^{\mathrm{R3}}$ & 230 & 100 & 0.4 & 0.38 & 1 & 30.4 & 22.8 & III-b \\
\hline M30d04 R1 & 230 & 300 & 0.4 & 0.38 & 1 & 28.0 & 28.8 & III-B \\
\hline M30d04 R2 & 230 & 300 & 0.4 & 0.38 & 1 & 27.8 & 34.0 & III-B \\
\hline M30d04 R3 & 230 & 300 & 0.4 & 0.38 & 1 & 27.5 & 33.5 & III-B \\
\hline M30d12 R1 & 230 & 300 & 0.8 & 0.56 & 1 & 21.9 & 62.2 & III-P \\
\hline $\mathrm{M} 30 \mathrm{~d} 12^{\mathrm{R} 2}$ & 230 & 300 & 0.8 & 0.56 & 1 & 22.2 & 63.4 & III-P \\
\hline $\mathrm{M} 30 \mathrm{~d} 12^{\mathrm{R} 3}$ & 230 & 300 & 0.8 & 0.56 & 1 & 22.3 & 63.1 & III-P \\
\hline M30a04660 & 230 & 30 & 0.4 & 0.38 & 12.0 & 29.8 & 5.2 & I \\
\hline M30b04660 & 230 & 50 & 0.4 & 0.38 & 11.6 & 29.4 & 10.1 & I \\
\hline M30c04660 & 230 & 100 & 0.4 & 0.38 & 3.0 & 30.2 & 30.1 & III-b \\
\hline M30g04660 & 230 & 1 & 0.4 & 0.38 & 120 & 28.0 & 4.1 & I \\
\hline
\end{tabular}




\section{SUPPLEMENTARY VIDEOS}

855

856

Each regime discussed in this paper has been represented by a selected numerical model, displayed in all of the figures. For each of them, a video has been made showing the evolution through time of the primordial composition field as well as the potential temperature field. For the discussion of the evolution of these models, the reader is referred to Section 3.1 of the paper.

Supplementary Video 1 - evolution of model M30a00, reference case for regime I

Supplementary Video 2 - evolution of model M30c26, reference case for regime II-L Supplementary Video 3 - evolution of model M30d16, reference case for regime II-T Supplementary Video 4- evolution of model M30f20, reference case for regime II-O Supplementary Video 5 - evolution of model $M 30 c 04$, reference case for regime III- $b$ Supplementary Video 6 - evolution of model M30d04, reference case for regime III-B Supplementary Video 7- evolution of model M30d12, reference case for regime III-P Supplementary Video 8 - evolution of model M30b14, reference case for regime III-D 